\title{
Open Data Model Parameterization of a Second-Life Li-ion Battery
}

\author{
Pedro V. H. Seger ${ }^{\mathrm{a}, *}$, Eddy Coron ${ }^{\mathrm{b}}$, Pierre-Xavier Thivel ${ }^{\mathrm{c}}$, Delphine Riu ${ }^{\mathrm{a}}$, Mikael Cugnet $^{\mathrm{b}}$, Sylvie Genies ${ }^{\mathrm{b}}$ \\ ${ }^{a}$ Université Grenoble Alpes, CNRS, Grenoble INP, G2Elab, F-38000 Grenoble, France. \\ ${ }^{b}$ Université Grenoble Alpes, CEA, LITEN, F-38000 Grenoble, France. \\ ${ }^{c}$ Université Grenoble Alpes, Université Savoie Mont Blanc, CNRS, Grenoble INP, LEPMI, F-38000 Grenoble, France.
}

\begin{abstract}
With the fast expansion of Electric and Hybrid Vehicles, the demand of Li-ion batteries is increasing exponentially. This creates an opportunity for a second life of these cells once they are no longer suitable for their original application. An accurate modelling of the second life can be a powerful tool for these new applications. In this work, we propose a complete second life model parameterization for a Li-Ion cell, with its parameters based on experimental data of NMC/LMO cells cycled through their first and second lives. The resulting model parameters span a State of Health from $80 \%$ to $50 \%$ of the cell original capacity, a State of Charge from 0 to $100 \%$, two current values and two first life temperature points. The model parameters are presented in an open data fashion in the form of look-up tables, ready to be implemented in simulation softwares.
\end{abstract}

Keywords: Lithium-Ion, Second-Life Battery, Experimental Data, Open Data Model, Ageing, Parametric Uncertainty

\section{Introduction}

In recent years, a significant expansion in the popularity of Electric Vehicles (EVs) has been observed, and is expected to continue to do so in the next decades [1]. One consequence of such an expansion is that the demand of Li-Ion Batteries (LIBs) is also increasing at a fast pace. As EV batteries are usually discarded at a State of Health $(\mathrm{SoH})$ of $80 \%$, there is a growing availability of SecondLife Batteries (SLBs).

As mentioned in [2, several studies estimate a SLB availability on the order of several GWh to some TWh over the next decades. A widespread use of SLBs is expected to have a positive economical and environmental impact, and comes hand in hand with the renewable energies context [2, 3. This creates room for several interesting applications of SLBs, such as:

- Energy storage for residential applications [4] 6 ;

- Support for renewable energies (photovoltaic, wind turbines), from residential to industrial power levels [7, 8;

- Support for electrical grids, such as peak load management 4, 9];

- Charging stations for EVs, Vehicle to Grid [9, 10;

- Less demanding mobile applications [11.

\footnotetext{
${ }^{*}$ Corresponding author

Email address: pedro.von-hohendorff-seger@grenoble-inp.fr (Pedro V. H. Seger)
}

Interesting reviews of SLB applications and current works can be found in [2, 3, 9,

An appropriate modelling of the SLB behaviour can be useful for simulation purposes. Currently, most publications on the subject focus on modelling the capacity loss as a function of known stress factors [10, 12,14.

Some interesting works focus on the second life evolution of a LIB parameters: 15] compared some parameters before and after ageing, but did not present the results as a function of the SoH; 16] presents the increment of some parameters due to distinct ageing conditions, but focuses on the SoH estimation technique; [17, 18, present parameters at some SoH points, but each SoH point comes from a cell at a different condition. Moreover, none of the mentioned works published their models in open data.

Therefore, to the extent of our knowledge, studies representing the evolution of each parameter of a LIB model during the second life are underexplored in the literature. In order to bridge this gap, we propose a complete electrical model parameterization for the second life of a NMC/LMO LIB. Each parameter of the model evolves as a function of the cell State of Charge (SoC), SoH and current. This model has the following features:

- A simple model and parameterization methodology, allowing easy implementation and reproducibility;

- Results spanning a SoH from $80 \%$ to $50 \%$ and a SoC from $0 \%$ to $100 \%$.

- Two current modes, representing a charge and a discharge; 
- Two different first life temperature conditions, targeting different ageing mechanisms;

- Experimental data from three cells for each first life condition, allowing us to evaluate the similarities;

- Results published in an open data fashion in the form of look-up tables.

The novelty of this work is in that we display the evolution of a common battery model parameters throughout the entire second life SoH range, as well as the impact of the first-life operation temperature. We believe these results can be useful for uncertainty analysis related to SLB applications.

This work is organized as it follows: Section 2 presents a literature review of SLB models and parametrization methods, our model of choice and some important definitions. Section 3 details the experimental setup used and the method to obtain our model parameters. Section 4 present the model results and discussion. Section 5 concludes this work.

\section{Li-Ion Cell Modelling and Definitions}

\subsection{Literature Review}

According to [19, 20, one can separate the most common types of LIB models available on the literature into some categories: statistical models, electrochemical models, electric equivalent circuit models, or a combination of these.

Statistical models are usually based on experimental data, using tools such as pattern extraction [21, Kalman filters [22, 23], regression techniques and other tools [24, 25. The objective is usually to analyse large amounts of data and find the best possible estimator. These models are, however, often limited by the data, not being representative of different situations.

Electrochemical models often use chemical or physical equations to accurately model a LIB, sometimes to the atomic level. This approach can also be used to accurately model the capacity loss or the thermal behaviour of a cell, for example. These models are also used to represent different battery technologies, such as new all-solid-state batteries, as in 26]. Some examples of such models can be found on [26 30]. Whereas their accuracy is a clear advantage, these models can be numerically complicated and have difficulty relating microscopic and macroscopic behaviours 31.

Electric Equivalent Circuits (EEC) represent the behaviour of a LIB using standard electrical elements, such as voltage sources, impedances and RLC elements. They can vary in complexity, going from as simple as a voltage source and a resistance to a model with impedances to represent complex, frequency-domain behaviours. Reviews of several of these models can be found in [2, 32, 34].

EEC models have the advantage of being computationally light and easy to understand and implement. They are, however, representative models, not being directly connected to the electrochemical phenomena at play.

The parameters of EEC models can be made variable in function of the stress factors that impact the LIB ageing. Common stress factors that have been explored in the literature are: Temperature 35 37, Current (C-rate) [37, 38, Overcharge and overdischarge [38, 39] and Depth of Discharge [38, 40, 41] of the cell.

Regarding the parameterization procedure for EEC models, two strategies are commonly found in the literature: current steps and Electrochemical Impedance Spectroscopy (EIS) [20].

EIS is a powerful tool for representing a LIB behaviour. It consists of applying small voltage perturbations on the LIB over a wide range of frequencies. This results on an impedance behaviour over the test frequencies. This impedance can, then, be represented by electrical elements, with varying degrees of accuracy and performance. Good examples of EIS being used to parameterize an EEC model can be found in $18,42,44$.

Despite its accuracy, performing an EIS requires specialized equipment, hindering its utilisation on some contexts: it is not practical, for instance, to disassemble a pack of batteries in order to characterize it.

Current steps are a simple and practical option to parameterize an EEC model. It consists of performing current steps of a known amplitude and measuring the ensuing voltage response. By using electrical circuit equations, one can find parameters that resemble said voltage-current behaviour. Good examples of this technique can be found in $14,36,37,45$.

Despite not containing as much information as an EIS, current pulses have the advantage of being simple to perform and only using current and voltage measurements. Usually, this data is already acquired and used by a Battery Management System (BMS).

\subsection{Formal Definitions}

In this work, some concepts related to li-ion batteries (LIBs) will be often used, and will be described in the next paragraphs.

The State of Health - SoH is defined as the actual capacity of the cell relative to its nominal capacity, as shown in Eq. 1. This means that for a cell with a nominal capacity $Q_{n}$ of $2.1 \mathrm{Ah}$, a $\mathrm{SoH}$ of $80 \%$ means an actual capacity $Q_{a}$ of $1.68 \mathrm{Ah}$.

$$
\operatorname{SoH}[\%]=\frac{Q_{a}}{Q_{n}} \cdot 100
$$

The State of Charge - SoC is defined as the current amount of charge $Q$ of the cell relative to its actual capacity $Q_{a}$, as shown in Eq. 2. In this work, the SoC is always relative to the actual capacity, not the nominal one - so that no matter the $\mathrm{SoH}$ of the cell, the SoC will always be 
between 0 and $100 \%$.

$$
S o C[\%]=\frac{Q}{Q_{a}} \cdot 100
$$

The First Life is defined as when a cell has a $S o H \in$ [100 80] \%. The Second Life begins then at a $\mathrm{SoH}=80 \%$.

The $C$-Rate is a way to represent the electric current going through the battery. In this work, we adopt the following convention: during the first life, $C$ means the nominal current of the cell; during the second life, $C$ means the current equivalent to the capacity at $\mathrm{SoH}=80 \%$. For a cell with a nominal capacity of $2.1 \mathrm{Ah}, C$ means $2.1 \mathrm{~A}$ on the first life and $1.68 \mathrm{~A}$ on the second life.

A positive value of current means the cell is being charged; a negative value stands for a discharge.

The Lithium Plating is a degradation mechanism of LIBs that causes metallic lithium to deposit around the anode of the cell, reducing its capacity. It is usually caused by overcharging or by cycling at low temperatures.

The Loss of Active Material (LAM) is a degradation mode that can happen in both anode and cathode, happening when the mass of these electrodes loses the capacity to be inserted with lithium particles. A comprehensive review of the degradation mechanisms and modes of Li-ion cells can be found in 46 .

\subsection{Model of Choice}

We choose to use a classic R-2RC model to represent our SLB. It consists of an open-circuit voltage $V_{o c}$, an internal resistance $R_{\text {int }}$ and two RC branches $R_{1}, C_{1}, R_{2}$, $C_{2}$, as it can be seen in Fig. 11. The voltage $V_{\text {cell }}$ represents the measurable voltage between the positive and negative electrodes of the cell.

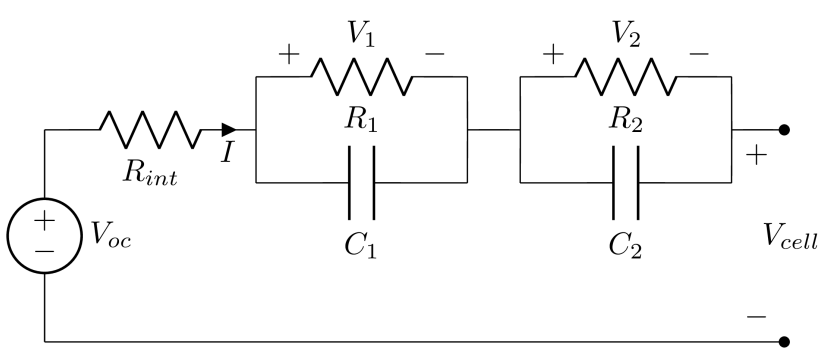

Figure 1: Illustration of the R-2RC model used in this work.

This model has been extensively used in the literature to represent Li-ion batteries and cells. As previously mentioned, it has the advantage of being simple and computationally light while retaining a good level of representation of the dynamic behaviour of a cell.

However, when using such a model, the evolution of both $\mathrm{SoC}$ and $\mathrm{SoH}$ has to be calculated separately. The most common SoC estimation technique is Coulomb Counting, where the current is measured and integrated in order to obtain the instantaneous capacity. The SoH estimation can be performed in several ways, using electrochemical equations and statistical models, for example.

The chosen parameterization strategy consists of performing current steps at fixed points of $\mathrm{SoC}$ and $\mathrm{SoH}$, as will be explained in Subsec. 3.2. Our model parameters are, then, a function of the $\mathrm{SoC}$, $\mathrm{SoH}$ and electrical current.

\section{Methods}

In this section, the methodology to obtain our model parameters is disclosed. Subsections 3.1 and 3.2 detail the experimental setup and the testing protocol used, respectively. A description of the data treatment and equations used to find the model parameters follows in Subsec. 3.3. and the extrapolation method for the missing parameter points is explained in Subsec. 3.4

\subsection{Experimental Setup}

The experimental tests were carried out in a testbed consisting of the following power supplies and instrumentation tools:

- An Arbin Bt2000 and a Maccor Series 4000 battery test systems, capable of performing preprogrammed battery charge and discharge cycles. They are also responsible for the acquisition of the current and voltage measurements of the Li-ion cells.

- A battery climatic chamber, responsible for managing the ambient temperature of the cells.

As shown in recent works [47, 48, this experimental testbed has been used to investigate the ageing mechanisms from an electrochemical perspective and to assess the second life viability of Li-ion cells. In [47, several cells are cycled through two distinct first life conditions, aiming to cause two different ageing mechanisms.

Then, some of these cells are also cycled through their second life. The data from these second life tests is used to develop the parameters in this work, and the details of these tests are explained in the following paragraphs.

The cell technology chosen for this study has a blend $\mathrm{NMC}+\mathrm{LMO}$ positive electrode, a graphite negative electrode and a nominal capacity of $2.1 \mathrm{Ah}$. This cell is considered to be a power cell due to its lower resistance and capacity when compared to other technologies (energy cells), and is suited for Electric Vehicles (EVs) application. The main characteristics of the investigated cell are disclosed on Table 1 below.

Six of those cells were subjected to the first life conditions detailed on Table 2 below. Cell identifiers are kept in order to be consistent with 47.

The different first life temperature conditions are chosen to explore two different ageing mechanisms: Loss of Active Material (LAM) for cycling at $25^{\circ} \mathrm{C}$ and Lithium Plating for cycling at $0^{\circ} \mathrm{C}$. 
Table 1: Investigated cell characteristics

\begin{tabular}{lc}
\hline Cell Format & 18650 \\
\hline Positive Electrode & $\mathrm{NMC}+\mathrm{LMO}$ \\
Specific Capacity & $158.5 \mathrm{mAh} \mathrm{g}^{-1}$ \\
\hline Negative Electrode & Graphite \\
Specific Capacity & $309 \mathrm{mAh}{ }^{-1}$ \\
\hline Cell Capacity & $2.1 \mathrm{Ah}$ \\
\hline Max. charge rate & $1 \mathrm{C}$ \\
\hline Max. discharge current & $-10 \mathrm{~A}$ \\
\hline Operating Temperature & $0{ }^{\circ} \mathrm{C}-45^{\circ} \mathrm{C}$ \\
\hline
\end{tabular}

Table 2: First life cycling protocols

\begin{tabular}{ccc}
\hline Cell Identifier & Cycling C-Rate & Cycling Temperature \\
\hline \hline$\# 1, \# 2, \# 3$ & $1 \mathrm{C} /-1 \mathrm{C}$ & $25^{\circ} \mathrm{C}$ \\
\hline$\# 7, \# 8, \# 9$ & $1 \mathrm{C} /-1 \mathrm{C}$ & $0{ }^{\circ} \mathrm{C}$ \\
\hline
\end{tabular}

The cycling of the cells during the first life is performed with a Depth of Discharge - DoD of $100 \%$, meaning the cells are fully charged and discharged after every cycle.

When these cells reach a SoH of $80 \%$, their second life begins. The second life protocol is the same for all 6 cells, with a cycling C-rate of $C / 2$ and a temperature of $25{ }^{\circ} \mathrm{C}$.

During the second life, a check-up protocol is carried out every 50 cycles. This routine, explained in detail in Subsec. 3.2, is useful to keep track of the $\mathrm{SoH}$ evolution and allows identifying the model parameters.

Even though the second life conditions are the same, we are able to find two distinct models, denoted $\mathbf{F L 2 5}{ }^{\circ} \mathbf{C}$ and $\mathbf{F L 0}{ }^{\circ} \mathbf{C}$ in the remainder of this work, for both first life conditions presented above.

\subsection{Experimental Characterization Test}

The methodology to obtain the model parameters consists of performing check-up tests at the beginning of the second life and then every 50 full cycles of charge and discharge.

As the life of a LIB usually last for hundreds or even thousands of cycles [2], we make the hypothesis that the SoH loss during a characterization test is negligible. This means that each test yields a set of parameters considered to be at a constant SoH.

A check-up consists of the following procedures, as previously mentioned in [47:

1. A $\mathrm{C} / 2$ discharge in order to fully discharge the cell;

2. A C/10 cycle of charge and discharge;

3. Two $\mathrm{C} / 2$ cycles of charge and discharge;

4. A charge consisting of $\mathrm{C}$ current steps at 10 SoC points. A C $/ 2$ charge is carried out between the steps in order to bring the cell to the next SoC. Before each step, there is a one-hour resting time (with no current);
5. A discharge consisting of $-2 \mathrm{C}$ current steps at $10 \mathrm{SoC}$ points. Similarly to the previous procedure, a $-\mathrm{C} / 2$ discharge and the one-hour resting time are observed between each step.

6. A C/2 charge to $S o C=50 \%$.

The current steps mentioned on procedures 4 and 5 of the list above are carried out at precise points of $\mathrm{SoC}$ and last for $10 \mathrm{~s}$. The SoC points are, for a:

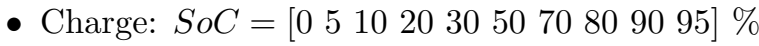

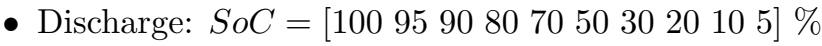

This characterization routine (procedures 4 and 5 only) is illustrated in Fig. 2.

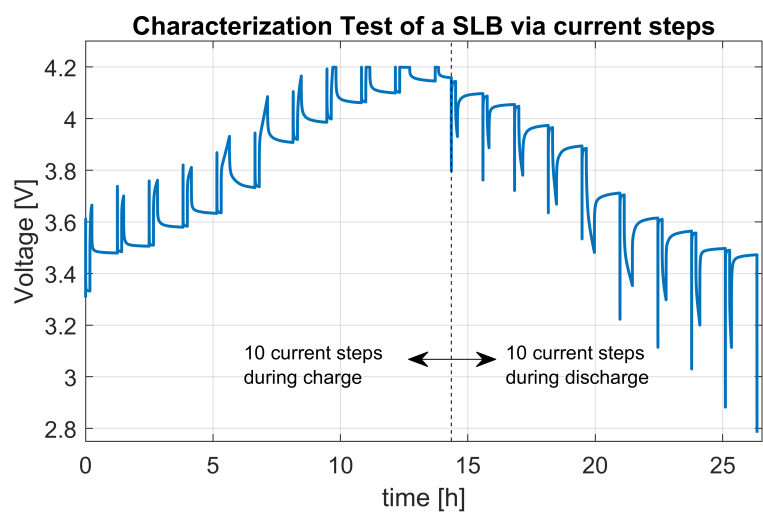

Figure 2: Characterization Test of a SLB via current steps

However, it is not to safe to do a charging current step at $S o C=100 \%$ or a discharging step at $S o C=0 \%$, as it would mean overcharging and overdischarging the Liion cell, respectively. Moreover, the final charging current steps usually incur in a voltage saturation of the charging station, as the safety limit of $V_{\text {cell }}=4.2 \mathrm{~V}$ is reached. This can also be seen in Fig. 2 .

It is not possible to find parameters for our model on these SoC points. In order to circumvent this and have a complete simulation model, extrapolation of the parameters on these points is needed. This issue will be discussed in Subsec. 3.4.

\subsection{Parameter Calculation}

As previously mentioned in Subsec. 2.1, using current steps do parameterize a battery model is a common yet powerful strategy. Even though it does not yield frequencydomain information as an Electrochemical Impedance Spectroscopy (EIS), it has the advantages of being simple, noninvasive and requiring only current and voltage measurements.

Moreover, the evolution of parameters as the internal resistance is often used as a $\mathrm{SoH}$ estimator and prognostic tool [13. Such a parameter can be easily obtained with current and voltage measurements. 
By analyzing the voltage response to the current steps data, we can quickly see the importance of a model that considers the evolution of the RC parameters. Figure 3 shows two discharging current step responses on a cell at the same SoH, but in two different points of SoC. The clear difference of resistive and capacitive effect is highlighted.

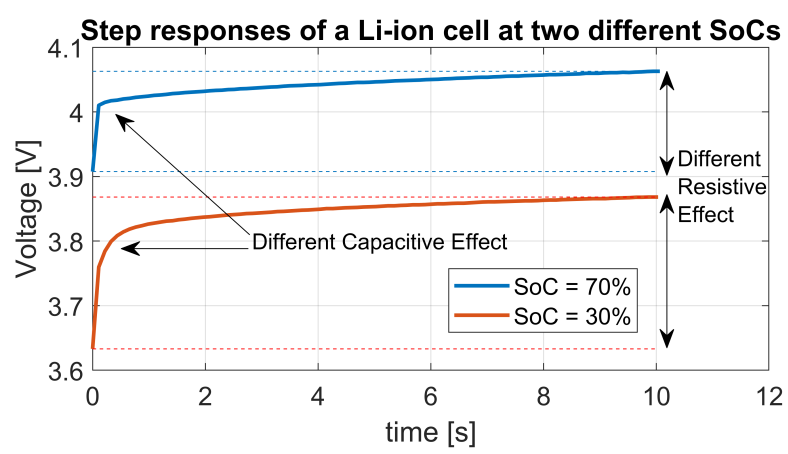

Figure 3: Illustration of the different RC behaviour of cell \#1 for a charging current, under different SoC values and a SoH of $80.3 \%$.

By knowing the voltage time response to a constant current step, we can use circuit equations to find the parameters of our model that will best fit the voltage vs. current pattern. The time-domain behaviour of our chosen cell circuit (Fig. 1) can be described by Eq. 3

$$
V_{\text {cell }}=V_{o c}-R_{\text {int }} \cdot I-V_{1}-V_{2}
$$

Where $I$ is the current. The voltages $V_{1}, V_{2}$ across the capacitors have the following differential formulation, where $i=1$ or 2 :

$$
\frac{d V_{i}}{d t}=-\frac{1}{R_{i} \cdot C_{i}}\left(V_{i}-R_{i} \cdot I\right)
$$

If we consider the initial voltage across the capacitors as zero, we can solve the differential equations and rearrange the terms in order to obtain Eq. 5 below:

$$
V_{\text {cell }}=V_{\text {oc }}-\left(R_{\text {int }}+R_{1}+R_{2}\right) \cdot I+R_{1} \cdot I \cdot e^{-\frac{t}{R_{1} \cdot C_{1}}}+R_{2} \cdot I \cdot e^{-\frac{t}{R_{2} \cdot C_{2}}}
$$

However, fitting the curve with this equation does not yield the best results. The reason is that the experimental test bed used does not have a fixed sampling rate, so the first measurement after the current step is applied usually takes $100 \mathrm{~ms}$. After this point, the sampling rate increases to match the voltage dynamics.

Fitting without taking this in consideration yields a small value of $R_{\text {int }}$, as the fitting algorithm finds the optimal solution with a strong exponential behaviour. To avoid this inconsistency, we calculate the internal resistance as:

$$
R_{\text {int }}=\frac{V_{c e l l}^{100 m s}-V_{o c}}{I}
$$

Where the open-circuit voltage $V_{o c}$ is the cell voltage just before the current step. This is a valid assumption as there is an one-hour resting time before the step.

Equation 6 means that we consider that the voltage variation from 0 to $100 \mathrm{~ms}$ is exclusively due to the internal resistance. Then, we can fit the rest of the curve with an equation similar to (5), but without the effect of $R_{\text {int }}$, as in (7):

$$
V_{\text {cell }}=V_{o c}-b-d+b \cdot e^{-c \cdot t}+d \cdot e^{-f \cdot t}
$$

Where:

$$
\begin{gathered}
b=R_{1} \cdot I \\
c=\frac{1}{C_{1} \cdot R_{1}} \\
d=R_{2} \cdot I \\
f=\frac{1}{C_{2} \cdot R_{2}}
\end{gathered}
$$

When the curve fitting algorithm finds the values of the terms $b, c, d$ and $f$ of Eqs. 8] 11] above, we can then find the parameters $R_{1}, C_{1}, R_{2}$ and $C_{2}$, as we have four equations and four variables.

Figure 4 below illustrates this idea: the internal resistance is calculated at the first $100 \mathrm{~ms}$ of data as mentioned in Eq. 6, and the rest of the data is used for the curve fitting described in Eqs. 7 71 .

In Fig. 4, the voltage and current behaviours are shown for a cell subjected to a charging current. The cell had a $S o H=80.3 \%$ and a $S o C=50 \%$ at the moment of the current step.

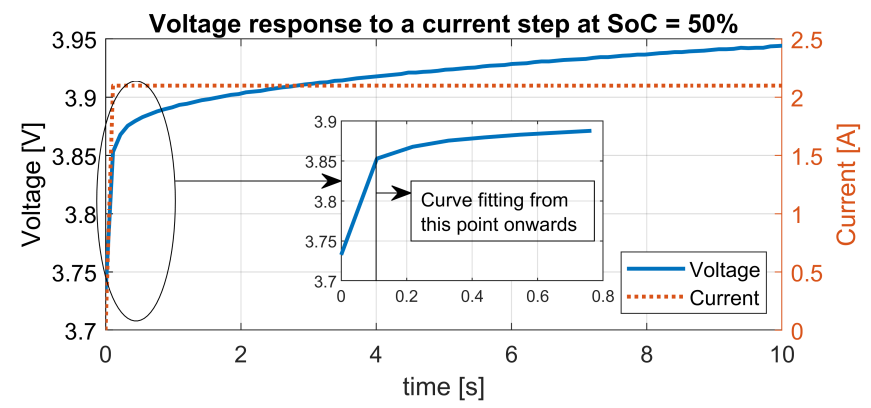

Figure 4: Voltage response to a current step of cell \#1 at a SoC of $50 \%$ and a SoH of $80.3 \%$

Doing so allows us to obtain a set of parameters that can very closely represent the actual behaviour of the Liion cell. Figure 5 below shows a comparison between the experimental data and a simulation carried out on Simulink with the parameters found. The simulation data is sampled at the same rate than the experimental data. In this case, a $R^{2}$ of $99.89 \%$ is obtained.

We then carry out this method to the many SoC and SoH points where a current step has been applied, for 


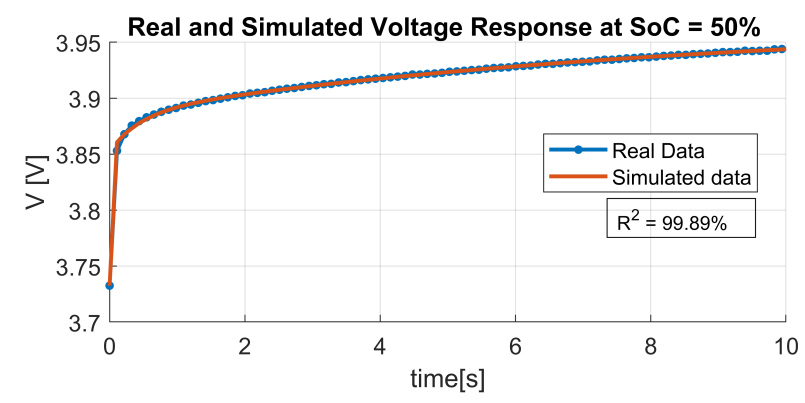

Figure 5: Real and simulated voltage response of cell \#1 at a SoC of $50 \%$ and a $\mathrm{SoH}$ of $80.3 \%$

both charging and discharging currents. A high value of $R^{2}>99 \%$ is always obtained when comparing real and simulated data. This allows us to obtain, for each parameter, an evolution in function of its $\mathrm{SoC}$ and $\mathrm{SoH}$, so that $V_{o c}$ is a function of the $\mathrm{SoH}$ and $\mathrm{SoC}$ and $R_{\text {int }}, R_{1}, R_{2}, C_{1}, C_{2}$ are functions of the $\mathrm{SoH}$, SoC and $I$.

We are then able to obtain curves such as the one shown in Fig. 6, where the parameter $R_{\text {int }}$ during a charge is plotted in function of its SoC - each line represents a $\mathrm{SoH}$ point. We can see that the internal resistance tends to increase with ageing and low values of SoC.

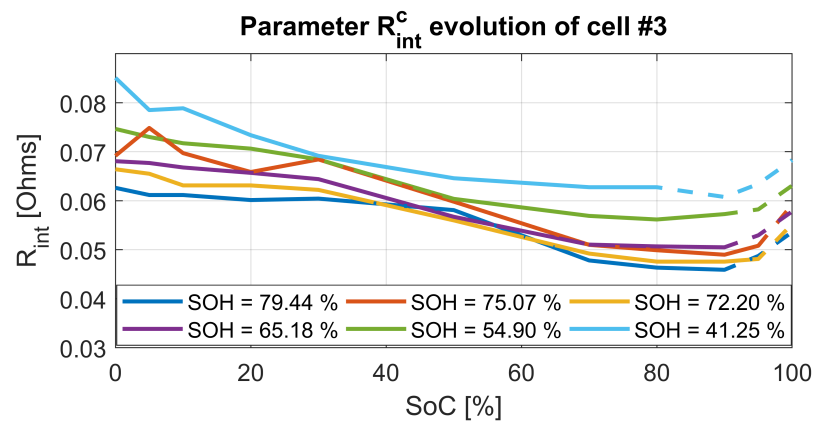

Figure 6: Evolution of the $R_{\text {int }}^{c}$ parameter as a function of its SoC and $\mathrm{SoH}$. Dashed lines represent extrapolated values. Cell \#3 of $\mathrm{FL} 25^{\circ} \mathrm{C}$

As we only have two points of current ( $\mathrm{C}$ for a charge and $-2 \mathrm{C}$ for a discharge), we will denote the parameters with a $c$ or $d$ superscript in the next sections, standing for charge and discharge, respectively. Therefore, $R_{i n t}^{d}$ means $R_{\text {int }}$ as a function of the SoC and $\mathrm{SoH}$ for a discharging current.

\subsection{Extrapolation of Missing Points}

As previously mentioned, the absence of current steps at certain SoC points - due to safety or voltage saturation of the battery cycler - makes it so that some parameters cannot be found at certain values of SoC.

Moreover, classic extrapolation strategies does not yield the best results, sometimes producing negative values for parameters with a downward tendency. An example can be seen in Fig. 6, the most complete curves have an upward tendency at high values of SoC, and it is known that
Li-ion cells have an increase in internal resistance close to $\mathrm{SoC}=100 \%$.

However, if we use a classic extrapolation algorithm, the two curves with the lowest $\mathrm{SoH}$ of Fig. 6 (colored light blue and green) would not show this upward tendency.

In order to circumvent this, we extrapolate based on the knowledge of the most complete curves. The procedure is explained on the paragraphs below.

For each parameter, we fit the most complete curve (usually the highest $\mathrm{SoH}$ one) with a polynomial function. The degree of this function is the one that yields the highest correlation and captures the physical effect of the curve.

We then fixate the dependent variables of said polynomial function and fit the other curves only by finding the independent term. By doing so, we are effectively replicating the same curve shape, shifting it on the y-axis.

\section{Results}

In this section, the obtained results for our open data model parameters will be detailed. In a first moment, we present the capacity fade of the cells over the second life cycles. Then, in Subsec. 4.2, the steps used to obtain a single range of values for each parameter are explained. The results are then presented and discussed in Subsec. 4.3 .

\subsection{Second-life capacity fade}

The capacity fade results of the cycled cells over their second life are presented in Fig. 7. Each marker represents a check-up test, carried out every 50 cycles, as explained in Subsec. 3.2. The cells that had a first life at $25^{\circ} \mathrm{C}$ and $0{ }^{\circ} \mathrm{C}$ are colored red and blue, respectively, and their first-life capacity fade is shown in [4].

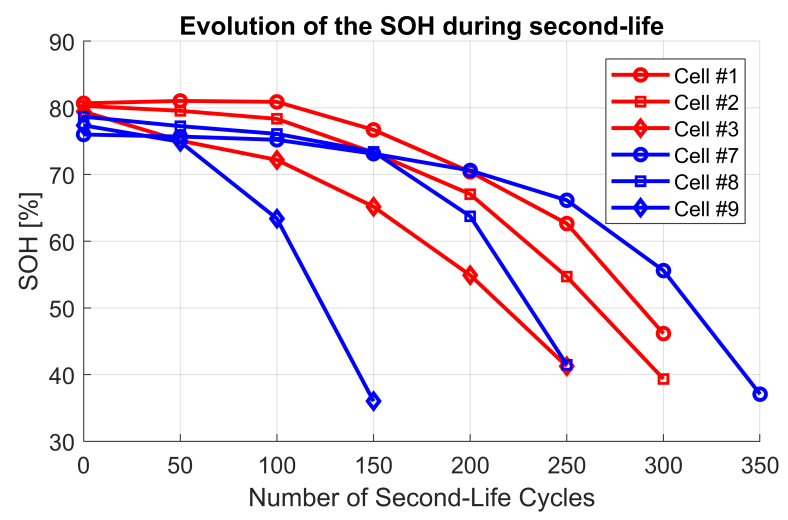

Figure 7: Second-life capacity fade of the investigated cells

One interesting outcome from this result is the uncertainty related to the capacity fade: identical cells, having the same first and second life utilization, can lead to a difference of hundreds of cycles over their lifespan. 


\subsection{Data Treatment}

A parametric evolution, as shown in Fig. 6, can be represented by a surface along two axis - the $\mathrm{SoC}$ and $\mathrm{SoH}$ values. This can be repeated for all parameters of each model, both for charging and discharging currents. These surfaces, their data treatment and the final parameters obtained will be explained in this section.

In Fig. 8, the obtained surfaces for the parameter $C_{1}$ during a discharge are shown for the 3 cells that had a first life at a temperature of $25^{\circ} \mathrm{C}$.

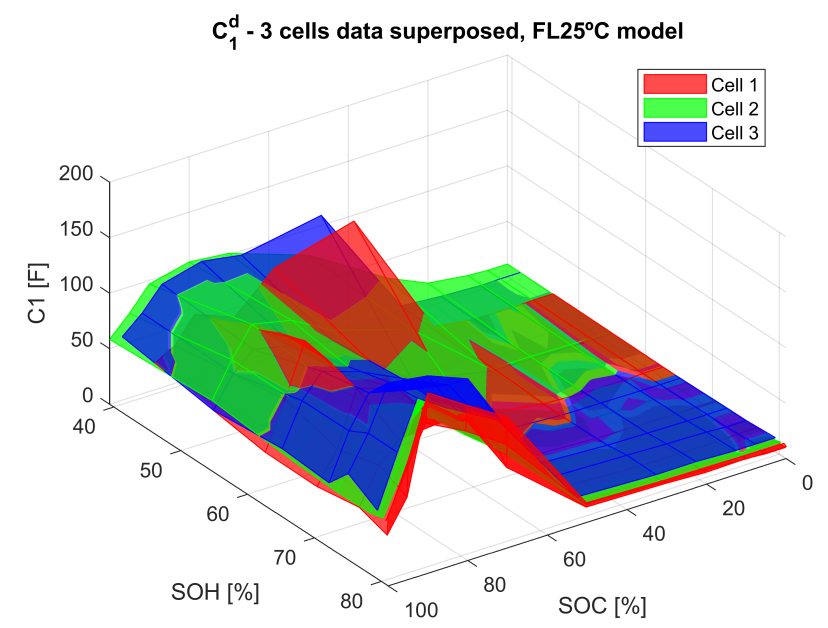

Figure 8: Surfaces of parameter $C_{1}^{d}$ for each cell of the FL $25^{\circ} \mathrm{C}$ Model

It is visible that the surfaces are very close, often superposed. This proximity is indeed observed for all parameters, both for charging and discharging, both for cells having a first life at $25^{\circ} \mathrm{C}$ and $0{ }^{\circ} \mathrm{C}$.

An interesting observation can be made when examining Figures 7 and 8. Even though the cells age at different rates, the parameter surfaces of each cell are still very close to each other.

For example, one cell can reach a $\mathrm{SoH}$ of $70 \%$ after 100 second-life cycles, whereas another cell only after 200 cycles. However, both cells will have very similar parameters at the $\mathrm{SoH}=70 \%$ point. This implies that the rate of ageing can substantially vary between cells, while the parameters seem to stay consistent with the SoH.

This indicates that, for any given parameter in our model, a single surface can be obtained by averaging the surfaces coming from each cell. In order to be able to average these surfaces, a virtual re-sampling on the $\mathrm{SoH}$ axis is made, as each cell has a different set of $\mathrm{SoH}$ values in which the current steps were applied. This is implemented through the function griddata on Matlab and allows us to fixate our second life range, which is chosen to be $S o H_{\text {values }}=\left[\begin{array}{ll}80757065605550\end{array}\right] \%$.

By following the methodology explained in the above paragraphs, we are able to find a surface of parametric evolution in terms of SoC and $\mathrm{SoH}$ for each parameter, for both charging and discharging currents. Figure 9 shows the surface of parameter $\mathrm{C} 1$ during a discharge, obtained by averaging the three surfaces shown in Fig. 8

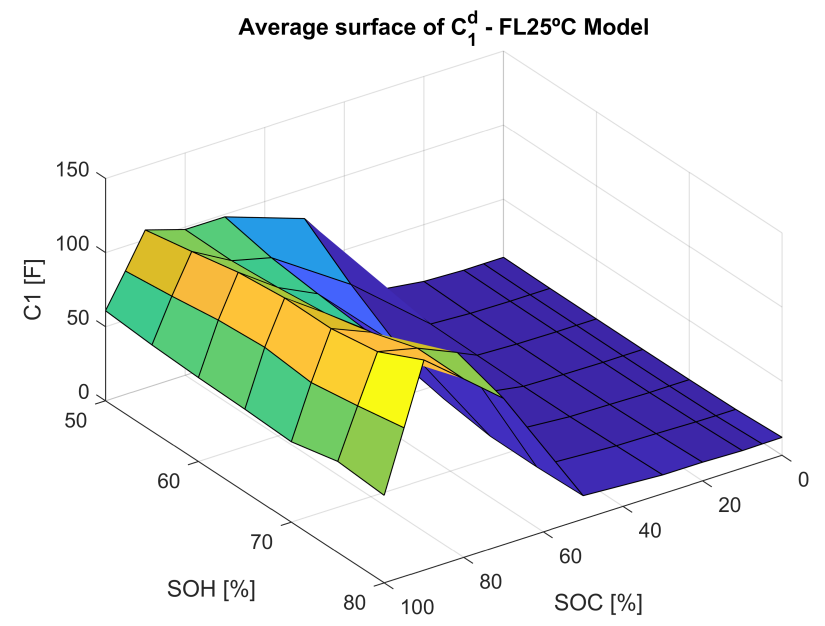

Figure 9: Average surface of parameter $C_{1}^{d}$ for the $\mathrm{FL} 25^{\circ} \mathrm{C}$ Model

In order to validate the assumption that the average surface is a good representation of the behaviour of the tested cells, we perform an analysis based on the Relative Error (RE). This is performed by calculating the absolute value of the REs of each parameter surface. We do this point-by-point, comparing each point of each cell parameter surface with the equivalent point of the averaged surface.

We are, in effect, comparing the surfaces of each cell (as shown in Fig. 8) with their average (as shown in Fig. 9. This can be represented by the Eq. 12 below:

$$
R E=\left|\frac{P_{i, j, k}-P_{i, j}^{a v g}}{P_{i, j}^{a v g}}\right|
$$

Where $\mathrm{P}$ is any of the parameters of our model $\left(V_{o c}\right.$, $\left.R_{\text {int }}, \ldots\right)$, for charge and discharge modes and for the $\mathrm{FL} 25^{\circ} \mathrm{C}$ and $\mathrm{FL} 0^{\circ} \mathrm{C}$ models; $i$ represents the SoC values, $j$ represents the $\mathrm{SoH}$ values, $k$ is the cell identifier (e.g. cell \#1,) and the subscript avg represents the average surface values, as shown in Fig. 9

This gives us, then, a multitude of RE values. If their distribution tends to be around a small RE, we can safely assume that the average surface is satisfactory. Figure 10 below shows the boxplots of the RE distribution for all parameters of the $\mathrm{FL} 25^{\circ} \mathrm{C}$ model.

We can see that for the majority of the parameters, the interquartile representing the 25 th and 75 th percentiles of data (represented by the blue box) is below $10 \%$, and the whisker representing $99.3 \%$ of the data (black dashed lines) is below $20 \%$. The only exception is for parameter $C_{1}^{c}$, where the box is around $20 \%$ and the whisker is around $30 \%$.

Similar results are obtained for the $\mathrm{FL} 0^{\circ} \mathrm{C}$ model and are shown in Fig. 11, with a slightly higher dispersion of the $R_{1}, C_{1}$ parameters. 


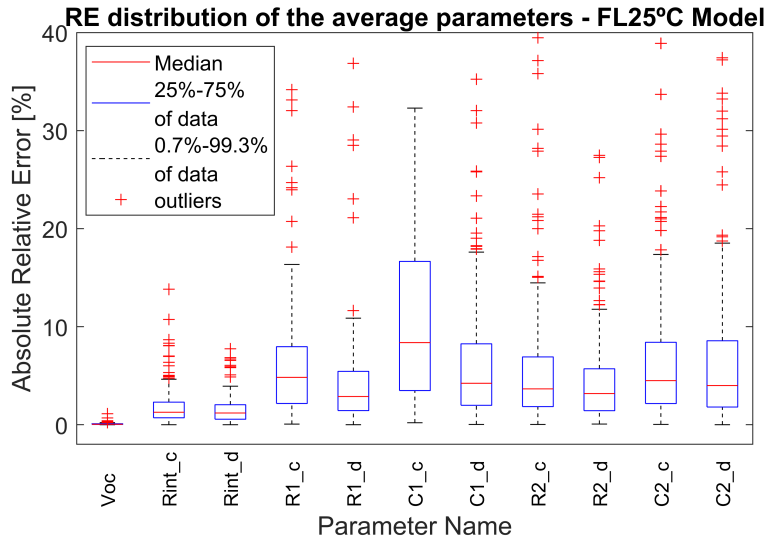

Figure 10: Boxplot of the Relative Error between experimental data and their average $-\mathrm{FL} 25^{\circ} \mathrm{C}$ model.

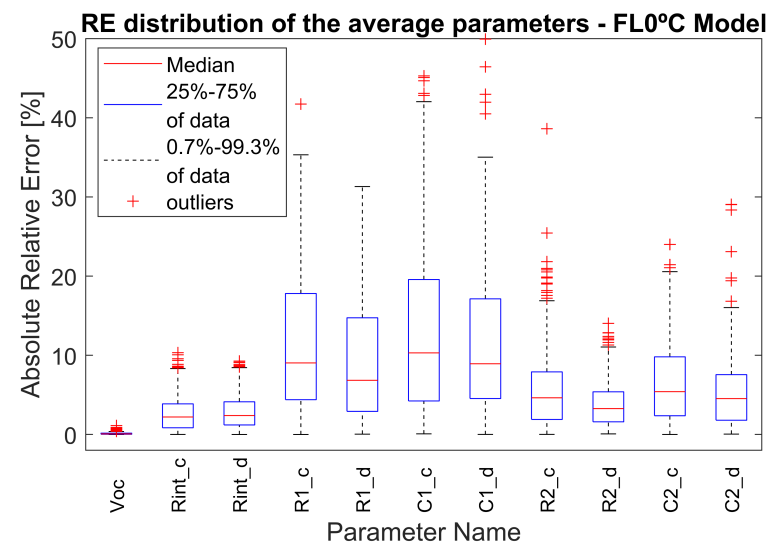

Figure 11: Boxplot of the Relative Error between experimental data and their average $-\mathrm{FL} 0^{\circ} \mathrm{C}$ model.

The variability observed on the RE distributions is considered to be acceptable, as per the experimental nature of our data and the usage of curve fitting techniques to obtain precise fits, as shown in Subsec. 3.3 .

The results shown in the boxplots can also be useful for parametric uncertainty estimation. For instance, when using our model, one can assume that the values of $R_{\text {int }}$ with a $10 \%$ uncertainty range are a good representation of the real-life observation.

\subsection{Model Parameters Results}

By following the discussed methodology, we are finally able to obtain the evolution of each parameter of our model in terms of the cell's SoC and SoH for both charge and discharge currents and for both $\mathrm{FL} 25^{\circ} \mathrm{C}$ and $\mathrm{FL} 0^{\circ} \mathrm{C}$ models. The results are shown in the Figs. 12 13 below. The data is also presented in table format at the Appendix, as per the open data nature of this article.

As the results are presented in the form of data tables, a user can utilize these data and curve fitting tools to obtain explicit functions for each parameter of the model (e.g. $\left.R_{\text {int }}^{d}=f(S o C, S o H)\right)$ in case such an implementation is desired.

A first detail that can be noticed when examining the results is the difference between the $\mathrm{FL} 25^{\circ} \mathrm{C}$ and $\mathrm{FLO}{ }^{\circ} \mathrm{C}$ models. The $0{ }^{\circ} \mathrm{C}$ model targeted a Lithium Plating ageing phenomena on its first life, whereas the $25^{\circ} \mathrm{C}$ one explored the Loss of Active Material. The results of the post-mortem analysis of these cells are published in [47.

When comparing the two models, we can see the effect of this on the parameters. The $0{ }^{\circ} \mathrm{C}$ model tends to have smaller resistive values for $R_{\text {int }}, R_{1}$ and $R_{2}$, specially on the beginning of the second life and in lower values of SoC. This can be seen in the evolution of the $R_{1}$ parameter, where a significant difference can be observed throughout the entire second life.

We can also see that the $0^{\circ} \mathrm{C}$ model has a stronger capacitive tendency, for both $C_{1}$ and $C_{2}$ parameters. The open-circuit voltage $V_{o c}$, however, is almost identical for the two models.

Another interesting observation is the difference of behaviour of the parameters for a charge and discharge current. For some parameters, such as the internal resistance $R_{\text {int }}$ and $R_{1}$, we can observe a similar behaviour and order of magnitude of the obtained values.

Parameters $R_{2}$ and $C_{1}$, on the other hand, show clear differences in both shape and value as a function of the current. Finally, parameter $C_{2}$ has a similar behaviour for medium values of SoC (around $50 \%$ ), but differs towards high and low SoC values.

A final interesting analysis of the results is regarding the impact of ageing on the parameters. Resistive parameters $R_{\text {int }}$ and $R_{2}$ tend to increase as the $\mathrm{SoH}$ declines, whereas $R_{1}$ does not seem to be heavily impacted. Capacitive parameters $C_{1}$ and $C_{2}$, on the other, tend to decrease in value as the cell ages. The $\mathrm{FL} 0^{\circ} \mathrm{C}$ model seems to be specially impacted by this behaviour.

One can also remark that even though the $\mathrm{FL} 0^{\circ} \mathrm{C}$ model suffered from Lithium Plating on its first life, both FL $25^{\circ} \mathrm{C}$ and $\mathrm{FL} 0^{\circ} \mathrm{C}$ models have their second life at a temperature of $25^{\circ} \mathrm{C}$, which privileges the Loss of Active Material. This is a possible explanation to the fact that the capacitive parameters $C_{1}$ and $C_{2}$ of the two models are significantly different in the beginning of the second life, but tend to smooth out at the end.

\subsection{Comparison of experimental and simulated data}

When the parameter surfaces of each cell were calculated, we compared the experimental and simulated data at every step, as illustrated in Fig. 5. However, our final model data consists of averaged parametric surfaces from several cells, as explained in Subsec. 4.2.

In order to validate the performance of our model, we compared the experimental and simulated data again. As we have hundreds of experimental voltage response curves, we choose to illustrate 6 cases, in which several values of our data set are tested. The details of these cases are presented in Table 3 below: 


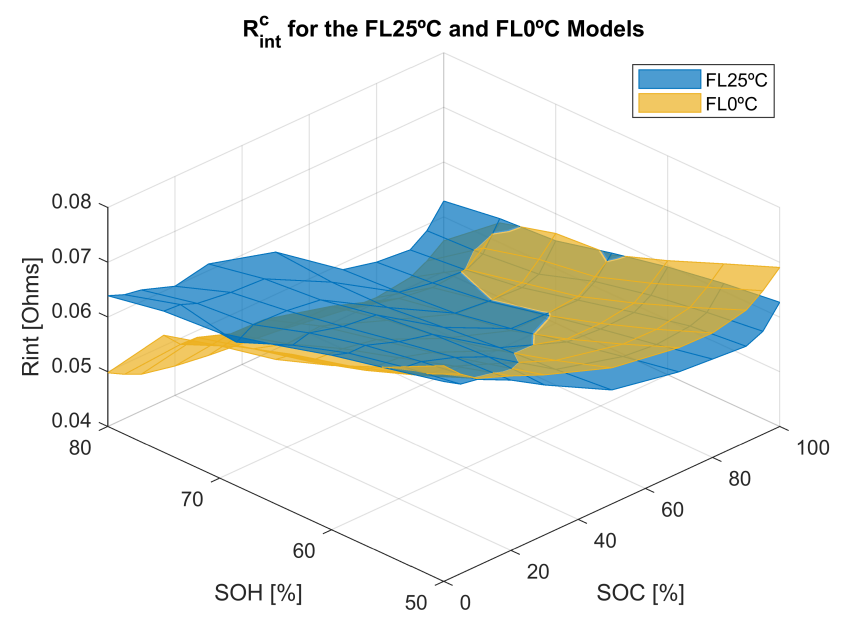

(a) Parameter $R_{\text {int }}$ for a charging current

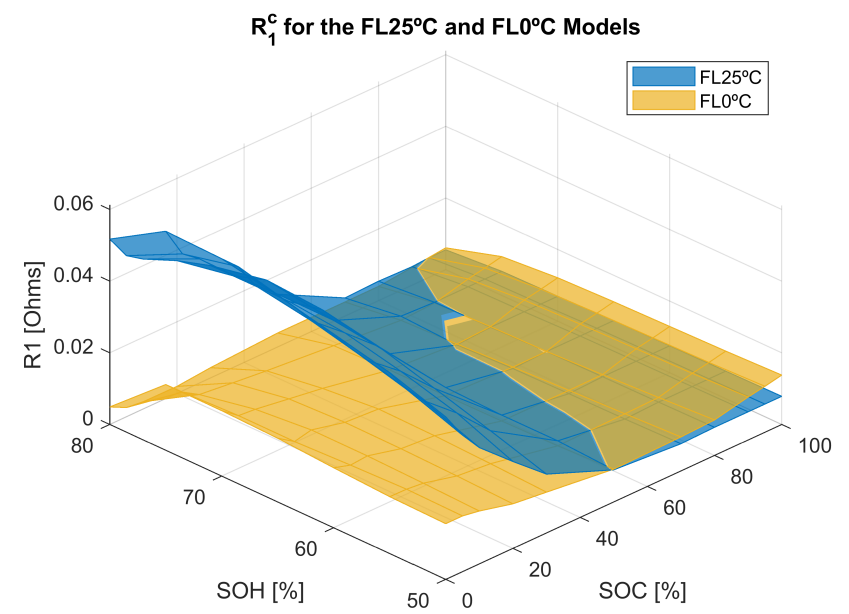

(c) Parameter $R_{1}$ for a charging current

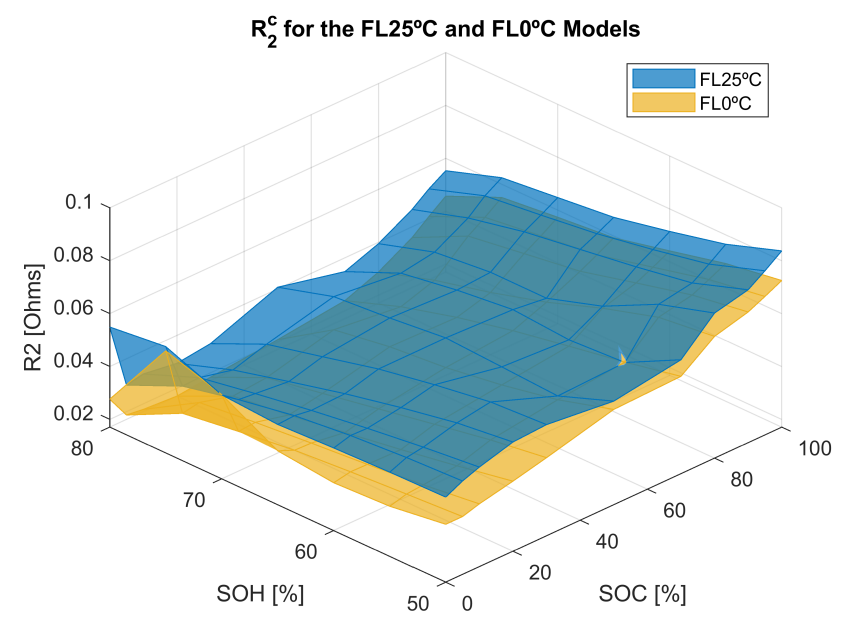

(e) Parameter $R_{2}$ for a charging current

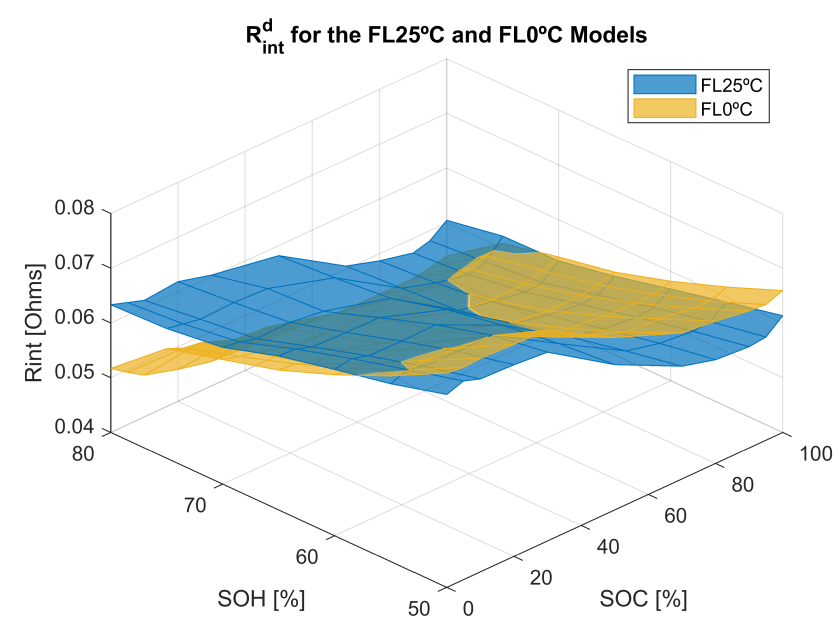

(b) Parameter $R_{\text {int }}$ for a discharging current

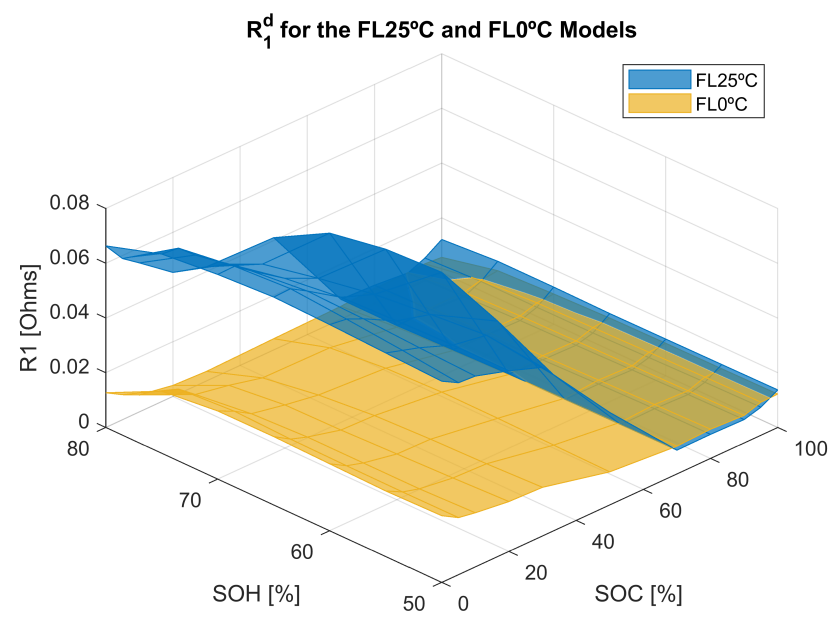

(d) Parameter $R_{1}$ for a discharging current

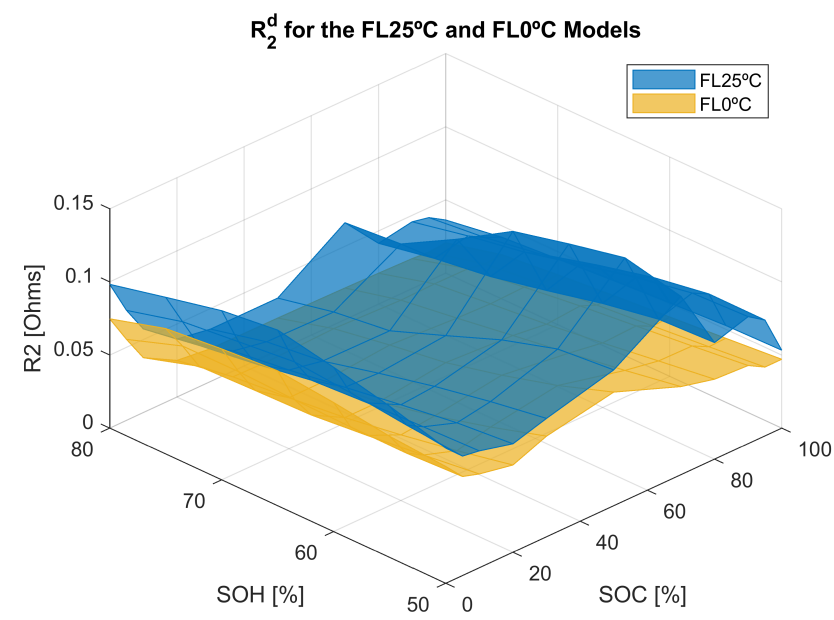

(f) Parameter $R_{2}$ for a discharging current

Figure 12: Surfaces of the resistive parameters for both charge and discharge currents and for both $\mathrm{FL} 25^{\circ} \mathrm{C}$ and $\mathrm{FL} 0^{\circ} \mathrm{C}$ models. 


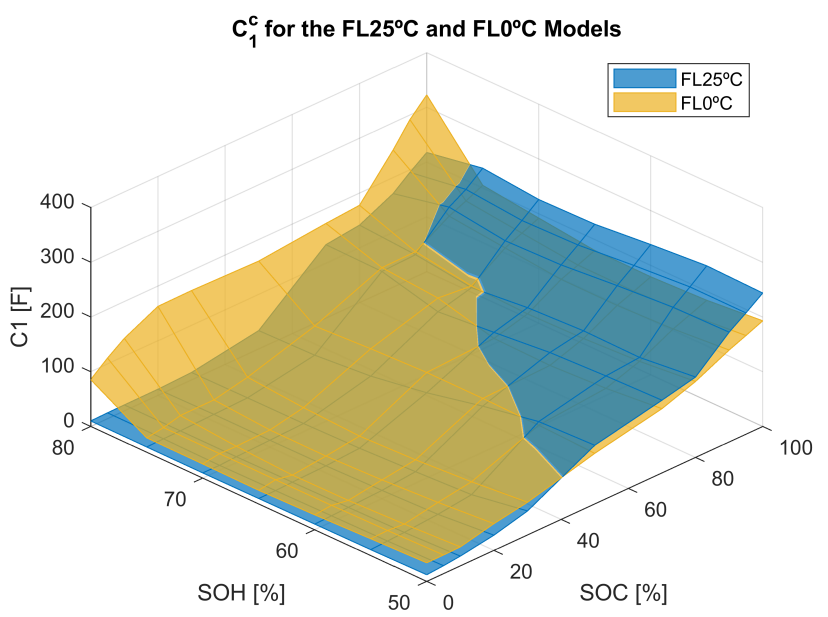

(a) Parameter $C_{1}$ for a charging current

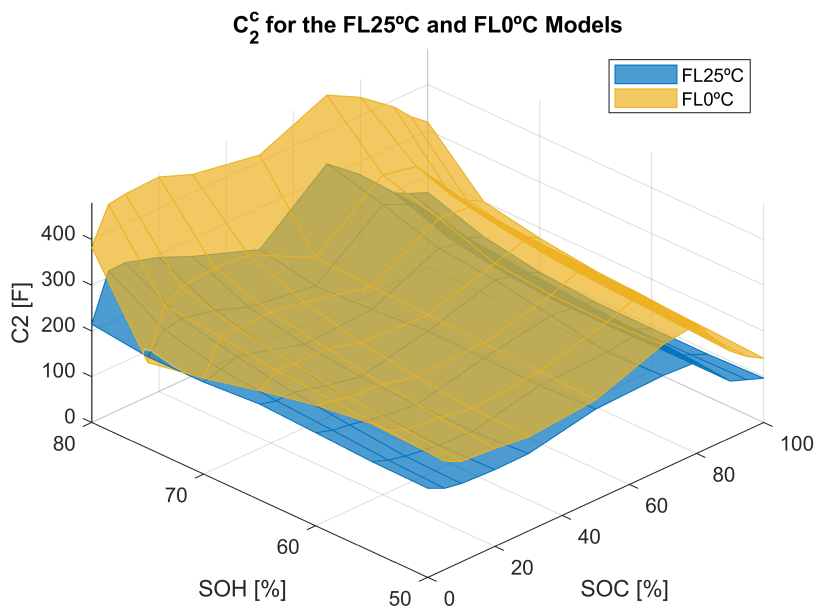

(c) Parameter $C_{2}$ for a charging current

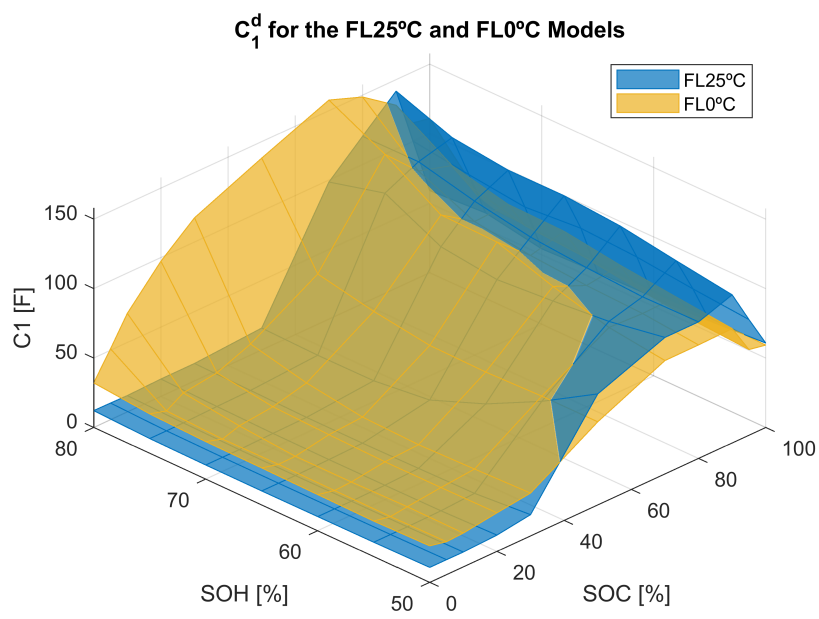

(b) Parameter $C_{1}$ for a discharging current

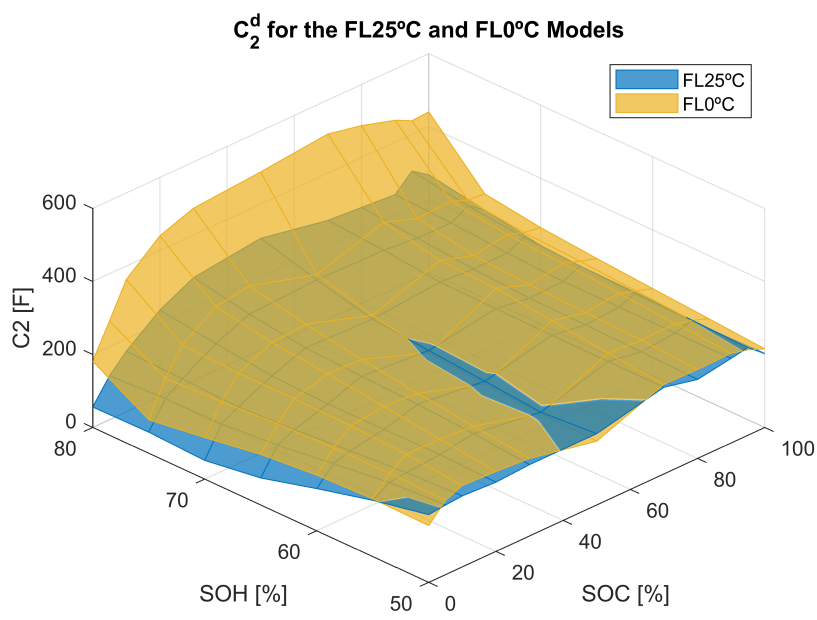

(d) Parameter $C_{2}$ for a discharging current

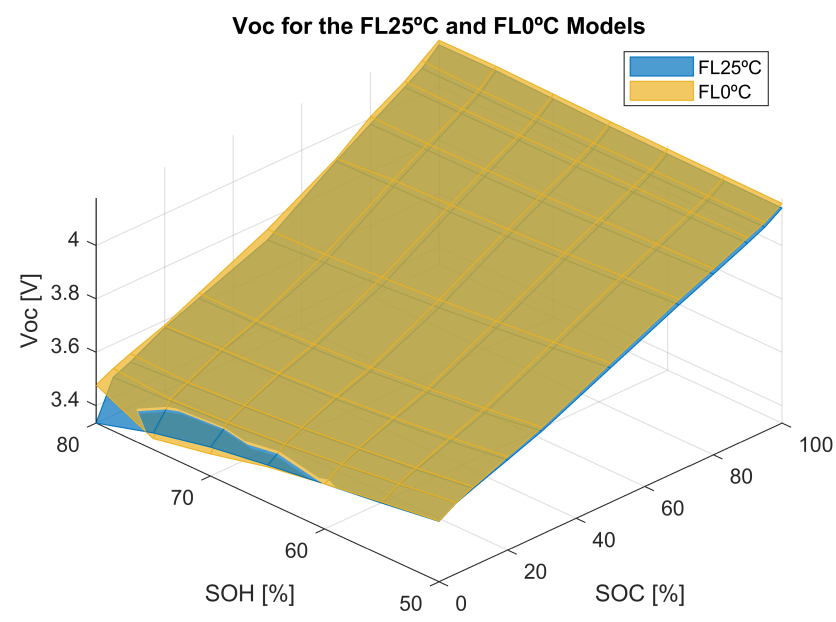

(e) Parameter $V_{o c}$

Figure 13: Surfaces of the capacitive parameters for both charge and discharge currents and open-circuit voltage for both $\mathrm{FL} 25^{\circ} \mathrm{C}$ and $\mathrm{FL} 0^{\circ} \mathrm{C}$ models. 
Table 3: Six cases for experimental and simulation comparison Case Cell Id Model SoC [\%] $\quad$ SoH [\%] Current mode

\begin{tabular}{cccccc}
\hline \hline 1 & $\# 1$ & $\mathrm{FL} 25^{\circ} \mathrm{C}$ & 0 & 75.1 & charge \\
\hline 2 & $\# 2$ & $\mathrm{FL} 25^{\circ} \mathrm{C}$ & 20 & 70.4 & charge \\
\hline 3 & $\# 3$ & $\mathrm{FL} 25^{\circ} \mathrm{C}$ & 90 & 54.8 & discharge \\
\hline 4 & $\# 7$ & $\mathrm{FL} 0{ }^{\circ} \mathrm{C}$ & 80 & 66.1 & charge \\
\hline 5 & $\# 8$ & $\mathrm{FL} 0{ }^{\circ} \mathrm{C}$ & 70 & 76.1 & discharge \\
\hline 6 & $\# 9$ & $\mathrm{FL} 0{ }^{\circ} \mathrm{C}$ & 50 & 63.4 & discharge \\
\hline
\end{tabular}

The comparison results are shown in Fig. 14 below. For the majority of cases, the curves are very close to one another. Sometimes it is possible to observe slight differences in the capacitive behaviour, as in Case 1, and/or resistive behaviour, as in Case 6 . This is explained by the usage of simulation parameters issuing from the average of several cells, as well as by the interpolation required to simulate precise values of $\mathrm{SoH}$, for example.

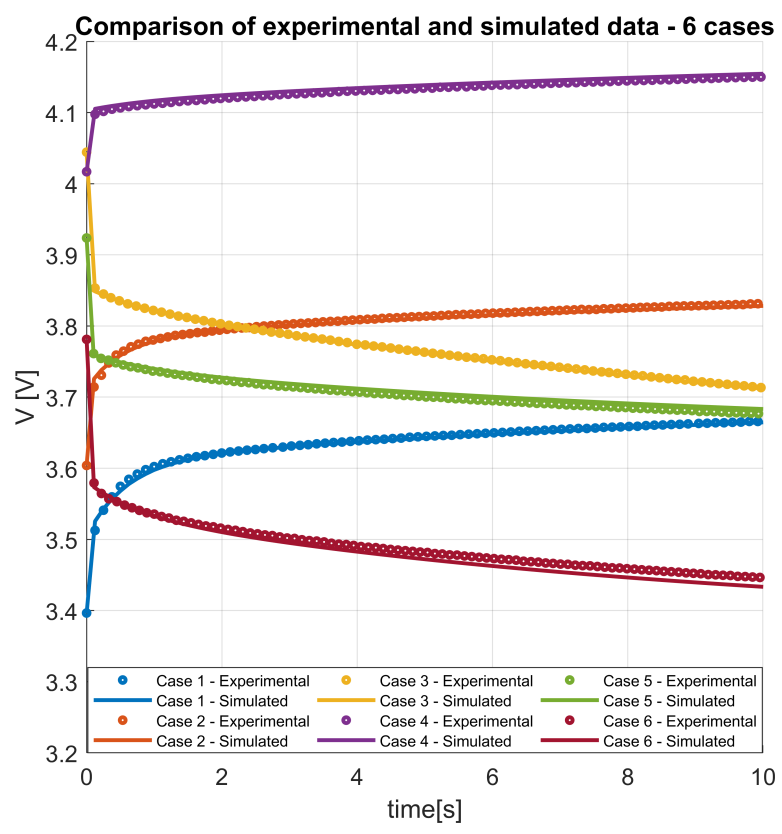

Figure 14: Comparison of experimental and simulated data for 6 cases

When analyzing these and other comparisons we observe that, for the worst cases, the voltage error is in the order of magnitude of tenths of millivolts. We consider this an acceptable result, all the more so because the objective of this work is not to achieve perfect simulation results, but to observe the evolution of the parameters during the second life.

Finally, it is worth noting that the parameters identified in this work represent the short-term dynamic response of a SLB. However, a user can couple our data tables with $\mathrm{SoC}$ and $\mathrm{SoH}$ estimators in order to obtain a model with variable parameters, which allows the simulation of long-term dynamics, such as charge-discharge cycles.

\section{Conclusion}

In this work, we present a complete, open data model parameterization for the second life of a $\mathrm{NMC}+\mathrm{LMO}$ technology Li-ion battery.

The parameters of this model are extracted from extensive testing of Li-ion cells that went through cycling ageing in well known conditions. Even though the model presented on this article is valid for a specific LIB technology, both the electrical equivalent model and the parameterization techniques are well known. This is made so that the methodology can easily be replicated in order to find simulation models for other battery technologies.

As several cells have been cycled, we are able to extract an average of each of the model's parameters. The variation of the parameters of each cell with regard to the average is also studied, giving an idea of the parametric uncertainty of the model.

Two different first life temperature conditions have been studied and presented, focusing on two different ageing mechanisms: Loss of Active Material and Lithium Plating. The impact of these first life conditions and of the electrical current (charge and discharge modes) can be clearly seen in the presented results.

This work bridges a gap in the literature, as it presents the complete evolution of all parameters of an electric equivalent circuit model as a function of the second life SoH, SoC, current and first life ageing mechanism.

Furthermore, all the results are publicly available - as they are presented in an open data fashion, we believe this model can be useful for simulation, academic and educational purposes.

\section{Acknowledgment}

This research is supported by the French National Research Agency under the "Investissements d'avenir" program (ANR-15-IDEX-02) through the Cross Disciplinary Program CIRCULAR.

\section{References}

[1] N. Rietmann, B. Hügler, and T. Lieven, "Forecasting the trajectory of electric vehicle sales and the consequences for worldwide CO2 emissions," Journal of Cleaner Production, vol. 261, p. 121038 , July 2020.

[2] E. Hossain, D. Murtaugh, J. Mody, H. M. R. Faruque, M. S. Haque Sunny, and N. Mohammad, "A Comprehensive Review on Second-Life Batteries: Current State, Manufacturing Considerations, Applications, Impacts, Barriers Potential Solutions, Business Strategies, and Policies," IEEE Access, vol. 7, pp. 73215-73252, 2019.

[3] M. H. S. M. Haram, J. W. Lee, G. Ramasamy, E. E. Ngu, S. P. Thiagarajah, and Y. H. Lee, "Feasibility of utilising second life EV batteries: Applications, lifespan, economics, environmental impact, assessment, and challenges," Alexandria Engineering Journal, vol. 60, pp. 4517-4536, Oct. 2021.

[4] E. Martinez-Laserna, E. Sarasketa-Zabala, I. Villarreal Sarria, D.-I. Stroe, M. Swierczynski, A. Warnecke, J.-M. Timmermans, S. Goutam, N. Omar, and P. Rodriguez, "Technical Viability of 
Battery Second Life: A Study From the Ageing Perspective," IEEE Transactions on Industry Applications, vol. 54, pp. 27032713, May 2018.

[5] L. Ahmadi, M. Fowler, S. B. Young, R. A. Fraser, B. Gaffney, and S. B. Walker, "Energy efficiency of Li-ion battery packs re-used in stationary power applications," Sustainable Energy Technologies and Assessments, vol. 8, pp. 9-17, Dec. 2014.

[6] C. Zhu, J. Xu, K. Liu, and X. Li, "Feasibility analysis of transportation battery second life used in backup power for communication base station," in 2017 IEEE Transportation Electrification Conference and Expo, Asia-Pacific (ITEC Asia-Pacific), (Harbin, China), pp. 1-4, IEEE, Aug. 2017.

[7] F. McLoughlin and M. Conlon, "Secondary Re-Use of Batteries From Electric Vehicles for Building Integrated Photo-Voltaic (BIPV) applications," PV CROPS Technical Report, Technological University Dublin, Apr. 2015.

[8] M. Alhadri, W. Zakri, R. Esmaeeli, A. H. Mohammed, S. R. Hashemi, H. Barua, H. Aliniagerdroudbari, and S. Farhad, "Analysis of Second-Life of a Lithium-Ion Battery in an Energy Storage System Connected to a Wind Turbine," in 2019 IEEE Power and Energy Conference at Illinois (PECI), (Champaign, IL, USA), pp. 1-8, IEEE, Feb. 2019.

[9] L. C. Casals, B. Amante García, and C. Canal, "Second life batteries lifespan: Rest of useful life and environmental analysis," Journal of Environmental Management, vol. 232, pp. 354-363, Feb. 2019.

[10] C.-L. Nguyen, E. Colicchio, P. Primiani, L. Viglione, K. AlHaddad, and L. Woodward, "A Cost-Effective Standalone Ebike Charging Station Powered by Hybrid Wind and Solar Power System Including Second-Life BESS," in 2020 IEEE Energy Conversion Congress and Exposition (ECCE), (Detroit, MI, USA), pp. 3684-3690, IEEE, Oct. 2020.

[11] H. Weiss, K. Schopf, and M. Zarkar, "High-performance lawnmower prototype with re-used Lithium Iron Phosphate battery," in 2014 12th International Conference on Actual Problems of Electronics Instrument Engineering (APEIE), (Novosibirsk, Russia), pp. 785-788, IEEE, Oct. 2014.

[12] Y. Jiang, J. Jiang, C. Zhang, W. Zhang, Y. Gao, and N. Li, "State of health estimation of second-life LiFePO4 batteries for energy storage applications," Journal of Cleaner Production, vol. 205, pp. 754-762, Dec. 2018.

[13] A. Basia, Z. Simeu-Abazi, E. Gascard, and P. Zwolinski, "Review on State of Health estimation methodologies for lithiumion batteries in the context of circular economy," CIRP Journal of Manufacturing Science and Technology, vol. 32, pp. 517-528, Jan. 2021.

[14] M. Chen and G. Rincon-Mora, "Accurate Electrical Battery Model Capable of Predicting Runtime and I-V Performance," IEEE Transactions on Energy Conversion, vol. 21, pp. 504-511, June 2006

[15] P. Hart, P. Kollmeyer, L. Juang, R. Lasseter, and T. Jahns, "Modeling of second-life batteries for use in a CERTS microgrid," in 2014 Power and Energy Conference at Illinois (PECI), (Champaign, IL, USA), pp. 1-8, IEEE, Feb. 2014.

[16] Z. Lyu, R. Gao, and L. Chen, "Li-Ion Battery State of Health Estimation and Remaining Useful Life Prediction Through a Model-Data-Fusion Method," IEEE Transactions on Power Electronics, vol. 36, pp. 6228-6240, June 2021.

[17] E. Locorotondo, V. Cultrera, L. Pugi, L. Berzi, M. Pasquali, N. Andrenacci, G. Lutzemberger, and M. Pierini, "Electrical lithium battery performance model for second life applications," in 2020 IEEE International Conference on Environment and Electrical Engineering and 2020 IEEE Industrial and Commercial Power Systems Europe (EEEIC / IECCPS Europe), (Madrid, Spain), pp. 1-6, IEEE, June 2020.

[18] E. Locorotondo, V. Cultrera, L. Pugi, L. Berzi, M. Pasquali, N. Andrenacci, G. Lutzemberger, and M. Pierini, "Impedance spectroscopy characterization of lithium batteries with different ages in second life application," in 2020 IEEE International Conference on Environment and Electrical Engineering and 2020 IEEE Industrial and Commercial Power Systems Europe
(EEEIC / IECPS Europe), (Madrid, Spain), pp. 1-6, IEEE, June 2020.

19] M. Tomasov, M. Kajanova, P. Bracinik, and D. Motyka, "Overview of Battery Models for Sustainable Power and Transport Applications," Transportation Research Procedia, vol. 40, pp. 548-555, 2019.

[20] Aoxia Chen and P. K. Sen, "Advancement in battery technology: A state-of-the-art review," in 2016 IEEE Industry Applications Society Annual Meeting, (Portland, OR, USA), pp. 1-10, IEEE, Oct. 2016.

[21] A. Barré, F. Suard, M. Gérard, and D. Riu, "Electric vehicles performance estimation through a patterns extraction and classification methodology," Journal of Power Sources, vol. 273, pp. 670-679, Jan. 2015.

[22] J. Kim and B. H. Cho, "State-of-Charge Estimation and Stateof-Health Prediction of a Li-Ion Degraded Battery Based on an EKF Combined With a Per-Unit System," IEEE Transactions on Vehicular Technology, vol. 60, pp. 4249-4260, Nov. 2011.

$23]$ A. Hasan, M. Skriver, and T. A. Johansen, "Exogenous Kalman Filter for State-of-Charge Estimation in Lithium-Ion Batteries," in 2018 IEEE Conference on Control Technology and Applications (CCTA), (Copenhagen), pp. 1403-1408, IEEE, Aug. 2018.

[24] B. Saha, K. Goebel, S. Poll, and J. Christophersen, "Prognostics Methods for Battery Health Monitoring Using a Bayesian Framework," IEEE Transactions on Instrumentation and Measurement, vol. 58, pp. 291-296, Feb. 2009.

[25] C. F. Chiasserini and R. R. Rao, "Pulsed battery discharge in communication devices," in Proceedings of the 5th annual ACM/IEEE international conference on Mobile computing and networking - MobiCom '99, (Seattle, Washington, United States), pp. 88-95, ACM Press, 1999.

[26] Z. Deng, X. Hu, X. Lin, L. Xu, J. Li, and W. Guo, "A Reduced-Order Electrochemical Model for All-Solid-State Batteries," IEEE Transactions on Transportation Electrification, vol. 7, pp. 464-473, June 2021.

[27] R. Ahmed, M. El Sayed, I. Arasaratnam, Jimi Tjong, and S. Habibi, "Reduced-Order Electrochemical Model Parameters Identification and SOC Estimation for Healthy and Aged LiIon Batteries Part I: Parameterization Model Development for Healthy Batteries," IEEE Journal of Emerging and Selected Topics in Power Electronics, vol. 2, pp. 659-677, Sept. 2014.

[28] M. Doyle, "Modeling of Galvanostatic Charge and Discharge of the Lithium/Polymer/Insertion Cell," Journal of The Electrochemical Society, vol. 140, no. 6, p. 1526, 1993.

[29] K.-C. Chiu, C.-H. Lin, S.-F. Yeh, Y.-H. Lin, C.-S. Huang, and K.-C. Chen, "Cycle life analysis of series connected lithiumion batteries with temperature difference," Journal of Power Sources, vol. 263, pp. 75-84, Oct. 2014.

[30] Q. Zhang and R. E. White, "Capacity fade analysis of a lithium ion cell," Journal of Power Sources, vol. 179, pp. 793-798, May 2008.

[31] A. Barré, B. Deguilhem, S. Grolleau, M. Gérard, F. Suard, and D. Riu, "A review on lithium-ion battery ageing mechanisms and estimations for automotive applications," Journal of Power Sources, vol. 241, pp. 680-689, Nov. 2013.

[32] H. He, R. Xiong, and J. Fan, "Evaluation of Lithium-Ion Battery Equivalent Circuit Models for State of Charge Estimation by an Experimental Approach," Energies, vol. 4, pp. 582-598, Mar. 2011

[33] H. Hinz, "Comparison of Lithium-Ion Battery Models for Simulating Storage Systems in Distributed Power Generation," Inventions, vol. 4, p. 41, Aug. 2019.

[34] S. Mousavi G. and M. Nikdel, "Various battery models for various simulation studies and applications," Renewable and Sustainable Energy Reviews, vol. 32, pp. 477-485, Apr. 2014.

[35] M. Swierczynski, D.-I. Stroe, and S. K. Kær, "Calendar ageing of $\mathrm{LiFePO} 4 / \mathrm{C}$ batteries in the second life applications," in 2017 19th European Conference on Power Electronics and Applications (EPE'17 ECCE Europe), pp. P.1-P.8, Sept. 2017.

[36] W. Mohammed, E. Kamal, A. Aitouche, and A. A. Sobaih, "Development Of Electro-Thermal Model of Lithium-Ion Bat- 
tery for Plug-In Hybrid Electric Vehicles," in 2018 7th International Conference on Systems and Control (ICSC), (Valencia), pp. 201-206, IEEE, Oct. 2018.

[37] Long Lam, P. Bauer, and E. Kelder, "A practical circuit-based model for Li-ion battery cells in electric vehicle applications," in 2011 IEEE 33rd International Telecommunications Energy Conference (INTELEC), (Amsterdam, Netherlands), pp. 1-9, IEEE, Oct. 2011.

[38] S. S. Choi and H. S. Lim, "Factors that affect cycle-life and possible degradation mechanisms of a Li-ion cell based on $\mathrm{Li}$ CoO2," Journal of Power Sources, vol. 111, pp. 130-136, Sept. 2002.

[39] H. Maleki and J. N. Howard, "Effects of overdischarge on performance and thermal stability of a Li-ion cell," Journal of Power Sources, vol. 160, pp. 1395-1402, Oct. 2006.

[40] N. Narayan, T. Papakosta, V. Vega-Garita, J. Popovic-Gerber, P. Bauer, and M. Zeman, "A simple methodology for estimating battery lifetimes in Solar Home System design," in 2017 IEEE AFRICON, (Cape Town), pp. 1195-1201, IEEE, Sept. 2017.

[41] S. B. Peterson, J. Apt, and J. Whitacre, "Lithium-ion battery cell degradation resulting from realistic vehicle and vehicle-togrid utilization," Journal of Power Sources, vol. 195, pp. 23852392, Apr. 2010.

[42] K. Goebel, B. Saha, A. Saxena, J. Celaya, and J. Christophersen, "Prognostics in Battery Health Management," IEEE Instrumentation $\&$ Measurement Magazine, vol. 11, pp. 33-40, Aug. 2008.

[43] G. Kaneko, S. Inoue, K. Taniguchi, T. Hirota, Y. Kamiya, Y. Daisho, and S. Inami, "Analysis of degradation mechanism of lithium iron phosphate battery," in 2013 World Electric Vehicle Symposium and Exhibition (EVS27), (Barcelona, Spain), pp. 1-7, IEEE, Nov. 2013.

[44] S. Waluś, C. Barchasz, R. Bouchet, and F. Alloin, "Electrochemical impedance spectroscopy study of lithium-sulfur batteries: Useful technique to reveal the $\mathrm{Li} / \mathrm{S}$ electrochemical mechanism," Electrochimica Acta, vol. 359, p. 136944, Nov. 2020.

[45] E. Vergori, F. Mocera, and A. Somà, "Battery Modelling and Simulation Using a Programmable Testing Equipment," Computers, vol. 7, p. 20, Mar. 2018

[46] C. R. Birkl, M. R. Roberts, E. McTurk, P. G. Bruce, and D. A. Howey, "Degradation diagnostics for lithium ion cells," Journal of Power Sources, vol. 341, pp. 373-386, Feb. 2017.

[47] E. Coron, S. Geniès, M. Cugnet, and P. X. Thivel, "Impact of Lithium-Ion Cell Condition on Its Second Life Viability," Journal of The Electrochemical Society, vol. 167, p. 110556 , July 2020.

[48] E. Coron, Diagnostic d'état de santé des batteries au lithium utilisées dans les véhicules électriques et destinées à des applications en seconde vie. $\mathrm{PhD}$ thesis, Université Grenoble Alpes, Grenoble, France, Feb. 2021. 
APPENDIX A - Parameters for Model FL $25^{\circ} \mathrm{C}$ :

Table .4: Parameter $R_{\text {int }}[\Omega]$ for a charging current

\begin{tabular}{||c||c|c|c|c|c|c|c|c|c|c|c||}
\hline \multirow{3}{*}{ SoH [\%] } & \multicolumn{9}{|c|}{ SoC $[\%]$} \\
\cline { 2 - 12 } & $\mathbf{0}$ & $\mathbf{5}$ & $\mathbf{1 0}$ & $\mathbf{2 0}$ & $\mathbf{3 0}$ & $\mathbf{5 0}$ & $\mathbf{7 0}$ & $\mathbf{8 0}$ & $\mathbf{9 0}$ & $\mathbf{9 5}$ & $\mathbf{1 0 0}$ \\
\cline { 2 - 13 } $\mathbf{7 5}$ & 0.0639 & 0.0627 & 0.0621 & 0.0600 & 0.0612 & 0.0577 & 0.0488 & 0.0474 & 0.0468 & 0.0489 & 0.0529 \\
\cline { 2 - 12 } $\mathbf{7 0}$ & 0.0658 & 0.0656 & 0.0644 & 0.0635 & 0.0632 & 0.0569 & 0.0494 & 0.0483 & 0.0478 & 0.0493 & 0.0544 \\
\cline { 2 - 12 } $\mathbf{6 5}$ & 0.0665 & 0.0634 & 0.0652 & 0.0649 & 0.0641 & 0.0570 & 0.0503 & 0.0497 & 0.0493 & 0.0504 & 0.0550 \\
$\mathbf{6 0}$ & 0.0690 & 0.0676 & 0.0684 & 0.0667 & 0.0660 & 0.0581 & 0.0522 & 0.0520 & 0.0518 & 0.0538 & 0.0575 \\
\cline { 2 - 11 } & 0.0719 & 0.0708 & 0.0708 & 0.0687 & 0.0672 & 0.0591 & 0.0545 & 0.0540 & 0.0542 & 0.0559 & 0.0597 \\
$\mathbf{5 5}$ & 0.0742 & 0.0730 & 0.0726 & 0.0705 & 0.0678 & 0.0598 & 0.0565 & 0.0559 & 0.0565 & 0.0575 & 0.0614 \\
$\mathbf{5 0}$ & 0.0765 & 0.0746 & 0.0740 & 0.0711 & 0.0674 & 0.0608 & 0.0585 & 0.0580 & 0.0575 & 0.0588 & 0.0627 \\
\hline
\end{tabular}

Table .5: Parameter $R_{\text {int }}[\Omega]$ for a discharging current

\begin{tabular}{||c||c|c|c|c|c|c|c|c|c|c|c||}
\hline \multirow{3}{*}{ SoH [\%] } & \multicolumn{9}{|c|}{ SoC $[\%]$} \\
\cline { 2 - 12 } & $\mathbf{0}$ & $\mathbf{5}$ & $\mathbf{1 0}$ & $\mathbf{2 0}$ & $\mathbf{3 0}$ & $\mathbf{5 0}$ & $\mathbf{7 0}$ & $\mathbf{8 0}$ & $\mathbf{9 0}$ & $\mathbf{9 5}$ & $\mathbf{1 0 0}$ \\
\cline { 2 - 13 } $\mathbf{8 0}$ & 0.0633 & 0.0623 & 0.0613 & 0.0619 & 0.0603 & 0.0581 & 0.0506 & 0.0487 & 0.0473 & 0.0481 & 0.0505 \\
\cline { 2 - 12 } & 0.0637 & 0.0631 & 0.0626 & 0.0628 & 0.0625 & 0.0588 & 0.0513 & 0.0494 & 0.0481 & 0.0490 & 0.0523 \\
$\mathbf{7 0}$ & 0.0650 & 0.0645 & 0.0637 & 0.0639 & 0.0631 & 0.0598 & 0.0519 & 0.0507 & 0.0496 & 0.0499 & 0.0525 \\
$\mathbf{6 5}$ & 0.0681 & 0.0680 & 0.0669 & 0.0667 & 0.0666 & 0.0624 & 0.0542 & 0.0529 & 0.0521 & 0.0524 & 0.0544 \\
$\mathbf{6 0}$ & 0.0704 & 0.0709 & 0.0700 & 0.0699 & 0.0700 & 0.0643 & 0.0565 & 0.0552 & 0.0545 & 0.0548 & 0.0568 \\
$\mathbf{5 5}$ & 0.0725 & 0.0736 & 0.0728 & 0.0727 & 0.0729 & 0.0657 & 0.0587 & 0.0572 & 0.0566 & 0.0570 & 0.0591 \\
$\mathbf{5 0}$ & 0.0752 & 0.0763 & 0.0752 & 0.0750 & 0.0745 & 0.0665 & 0.0606 & 0.0589 & 0.0585 & 0.0588 & 0.0613 \\
\hline
\end{tabular}

Table .6: Parameter $R_{1}[\Omega]$ for a charging current

\begin{tabular}{|c|c|c|c|c|c|c|c|c|c|c|c|}
\hline \multirow{2}{*}{ SoH [\%] } & \multicolumn{11}{|c|}{ SoC $[\%]$} \\
\hline & 0 & 5 & 10 & 20 & 30 & 50 & 70 & 80 & 90 & 95 & 100 \\
\hline 80 & 0.0517 & 0.0449 & 0.0418 & 0.0371 & 0.0314 & 0.0147 & 0.0051 & 0.0054 & 0.0051 & 0.0055 & 0.0055 \\
\hline 75 & 0.0611 & 0.0526 & 0.0491 & 0.0401 & 0.0345 & 0.0146 & 0.0072 & 0.0067 & 0.0067 & 0.0067 & 0.0067 \\
\hline 70 & 0.0606 & 0.0562 & 0.0488 & 0.0401 & 0.0334 & 0.0125 & 0.0064 & 0.0070 & 0.0070 & 0.0070 & 0.0070 \\
\hline 65 & 0.0576 & 0.0523 & 0.0462 & 0.0385 & 0.0304 & 0.0103 & 0.0069 & 0.0074 & 0.0074 & 0.0074 & 0.0074 \\
\hline 60 & 0.0541 & 0.0479 & 0.0424 & 0.0350 & 0.0259 & 0.0098 & 0.0071 & 0.0076 & 0.0076 & 0.0076 & 0.0076 \\
\hline 55 & 0.0505 & 0.0437 & 0.0384 & 0.0306 & 0.0213 & 0.0098 & 0.0073 & 0.0077 & 0.0077 & 0.0077 & 0.0077 \\
\hline 50 & 0.0453 & 0.0381 & 0.0324 & 0.0242 & 0.0164 & 0.0089 & 0.0076 & 0.0079 & 0.0079 & 0.0079 & 0.0079 \\
\hline
\end{tabular}

Table .7: Parameter $R_{1}[\Omega]$ for a discharging current

\begin{tabular}{|c|c|c|c|c|c|c|c|c|c|c|c|}
\hline \multirow{2}{*}{ SoH [\%] } & \multicolumn{11}{|c|}{ SoC [\%] } \\
\hline & 0 & 5 & 10 & 20 & 30 & 50 & 70 & 80 & 90 & 95 & 100 \\
\hline 80 & 0.0663 & 0.0589 & 0.0545 & 0.0453 & 0.0417 & 0.0410 & 0.0072 & 0.0067 & 0.0056 & 0.0082 & 0.0121 \\
\hline 75 & 0.0728 & 0.0721 & 0.0668 & 0.0578 & 0.0521 & 0.0521 & 0.0071 & 0.0072 & 0.0063 & 0.0090 & 0.0136 \\
\hline 70 & 0.0748 & 0.0749 & 0.0704 & 0.0620 & 0.0563 & 0.0557 & 0.0076 & 0.0074 & 0.0070 & 0.0090 & 0.0136 \\
\hline 65 & 0.0759 & 0.0761 & 0.0725 & 0.0645 & 0.0599 & 0.0567 & 0.0082 & 0.0077 & 0.0074 & 0.0091 & 0.0133 \\
\hline 60 & 0.0753 & 0.0745 & 0.0718 & 0.0653 & 0.0620 & 0.0483 & 0.0084 & 0.0083 & 0.0078 & 0.0095 & 0.0134 \\
\hline 55 & 0.0744 & 0.0725 & 0.0706 & 0.0659 & 0.0639 & 0.0380 & 0.0086 & 0.0087 & 0.0083 & 0.0099 & 0.0136 \\
\hline 50 & 0.0735 & 0.0701 & 0.0697 & 0.0660 & 0.0616 & 0.0338 & 0.0087 & 0.0088 & 0.0085 & 0.0102 & 0.0137 \\
\hline
\end{tabular}


Table .8: Parameter $R_{2}[\Omega]$ for a charging current

\begin{tabular}{|c|c|c|c|c|c|c|c|c|c|c|c|}
\hline \multirow{2}{*}{ SoH [\%] } & \multicolumn{11}{|c|}{ SoC [\%] } \\
\hline & 0 & 5 & 10 & 20 & 30 & 50 & 70 & 80 & 90 & 95 & 100 \\
\hline 80 & 0.0549 & 0.0300 & 0.0313 & 0.0294 & 0.0310 & 0.0406 & 0.0348 & 0.0395 & 0.0466 & 0.0514 & 0.0553 \\
\hline 75 & 0.0573 & 0.0394 & 0.0397 & 0.0367 & 0.0406 & 0.0468 & 0.0440 & 0.0461 & 0.0531 & 0.0586 & 0.0625 \\
\hline 70 & 0.0488 & 0.0441 & 0.0434 & 0.0421 & 0.0456 & 0.0485 & 0.0474 & 0.0482 & 0.0577 & 0.0611 & 0.0648 \\
\hline 65 & 0.0474 & 0.0478 & 0.0468 & 0.0473 & 0.0508 & 0.0508 & 0.0497 & 0.0482 & 0.0608 & 0.0638 & 0.0671 \\
\hline 60 & 0.0483 & 0.0500 & 0.0498 & 0.0518 & 0.0546 & 0.0496 & 0.0481 & 0.0549 & 0.0640 & 0.0676 & 0.0715 \\
\hline 55 & 0.0489 & 0.0515 & 0.0525 & 0.0558 & 0.0578 & 0.0484 & 0.0493 & 0.0655 & 0.0677 & 0.0718 & 0.0764 \\
\hline 50 & 0.0492 & 0.0524 & 0.0547 & 0.0583 & 0.0591 & 0.0562 & 0.0601 & 0.0719 & 0.0749 & 0.0791 & 0.0837 \\
\hline
\end{tabular}

Table .9: Parameter $R_{2}[\Omega]$ for a discharging current

\begin{tabular}{|c|c|c|c|c|c|c|c|c|c|c|c|}
\hline \multirow{2}{*}{ SoH [\%] } & \multicolumn{11}{|c|}{ SoC [\%] } \\
\hline & 0 & 5 & 10 & 20 & 30 & 50 & 70 & 80 & 90 & 95 & 100 \\
\hline 80 & $\begin{array}{l}0.0983 \\
\end{array}$ & 0.0752 & 0.0572 & $\begin{array}{c}0.0397 \\
\end{array}$ & 0.0359 & 0.0359 & 0.0662 & 0.0415 & 0.0456 & 0.0432 & 0.0362 \\
\hline 75 & 0.1071 & 0.0852 & 0.0635 & 0.0492 & 0.0449 & 0.0441 & 0.0694 & 0.0489 & 0.0536 & 0.0472 & 0.0422 \\
\hline 70 & 0.1157 & 0.0891 & 0.0688 & 0.0539 & 0.0494 & 0.0489 & 0.0903 & 0.0541 & 0.0603 & 0.0535 & 0.0450 \\
\hline 65 & 0.1201 & 0.0930 & 0.0752 & 0.0598 & 0.0588 & 0.0633 & 0.1133 & 0.0623 & 0.0695 & 0.0639 & 0.0478 \\
\hline 60 & 0.1123 & 0.0896 & 0.0774 & 0.0655 & 0.0674 & 0.0780 & 0.1224 & 0.0711 & 0.0784 & 0.0731 & 0.0503 \\
\hline 55 & 0.1034 & 0.0851 & 0.0787 & 0.0708 & 0.0747 & 0.0895 & 0.1306 & 0.0780 & 0.0853 & 0.0794 & 0.0525 \\
\hline 50 & 0.0924 & 0.0816 & 0.0799 & 0.0741 & 0.0809 & 0.0928 & 0.1219 & 0.0797 & 0.0868 & 0.0792 & 0.0533 \\
\hline
\end{tabular}

Table .10: Parameter $C_{1}[\mathrm{~F}]$ for a charging current

\begin{tabular}{|c|c|c|c|c|c|c|c|c|c|c|c|}
\hline \multirow{2}{*}{$\mathrm{SoH}$ [\%] } & \multicolumn{11}{|c|}{ SoC [\%] } \\
\hline & 0 & 5 & 10 & 20 & 30 & 50 & 70 & 80 & 90 & 95 & 100 \\
\hline 80 & 10.07 & 10.74 & 11.07 & 11.40 & 13.78 & 33.70 & 134.05 & 141.45 & 170.80 & 195.39 & 217.53 \\
\hline 75 & 9.69 & 10.40 & 10.82 & 12.67 & 14.53 & 35.92 & 132.27 & 134.62 & 193.19 & 211.46 & 235.98 \\
\hline 70 & 9.45 & 9.17 & 10.72 & 12.50 & 14.83 & 44.84 & 105.78 & 121.45 & 178.98 & 201.77 & 225.96 \\
\hline 65 & 9.83 & 10.18 & 11.40 & 12.97 & 16.82 & 61.54 & 115.35 & 132.13 & 181.91 & 204.25 & 227.96 \\
\hline 60 & 10.26 & 11.25 & 12.54 & 15.27 & 21.12 & 84.23 & 125.60 & 136.97 & 191.29 & 213.95 & 237.97 \\
\hline 55 & 10.68 & 12.28 & 13.96 & 18.67 & 26.29 & 103.18 & $\begin{array}{l}130.03 \\
\end{array}$ & 135.53 & 198.84 & 221.88 & 246.30 \\
\hline 50 & 12.02 & 14.40 & 17.78 & 27.70 & 43.68 & 107.04 & 132.80 & 146.87 & 200.49 & 221.50 & 243.69 \\
\hline
\end{tabular}

Table .11: Parameter $C_{1}[\mathrm{~F}]$ for a discharging current

\begin{tabular}{|c|c|c|c|c|c|c|c|c|c|c|c|}
\hline \multirow{2}{*}{ SoH [\%] } & \multicolumn{11}{|c|}{ SoC [\%] } \\
\hline & 0 & 5 & 10 & 20 & 30 & 50 & 70 & 80 & 90 & 95 & 100 \\
\hline 80 & 12.14 & 12.00 & 11.80 & 12.58 & 12.63 & 15.82 & 98.65 & 120.39 & 141.77 & 100.30 & 59.05 \\
\hline 75 & 10.57 & 10.57 & 10.72 & 11.39 & 11.8 & 14.82 & 109.19 & 120.69 & 126.93 & 94.68 & 61.48 \\
\hline 70 & 10.14 & 10.14 & 10.03 & 10.59 & 10.98 & 15.04 & 89.22 & 110.91 & 122.03 & 89.90 & 54.26 \\
\hline 65 & 10.04 & 10.04 & 9.95 & 10.32 & 10.98 & 19.75 & 84.16 & 103.62 & 122.20 & 93.21 & 55.75 \\
\hline 60 & 10.15 & 10.15 & 10.08 & 10.41 & 11.43 & 35.53 & 87.33 & 100.11 & 119.03 & 91.08 & 56.61 \\
\hline 55 & 10.28 & 10.28 & 10.22 & 10.61 & 12.03 & 55.95 & 91.21 & 97.77 & 112.61 & 86.75 & 58.15 \\
\hline 50 & 10.73 & 10.73 & 10.66 & 11.70 & 15.27 & 79.90 & 98.26 & 98.32 & 106.64 & 83.25 & 60.75 \\
\hline
\end{tabular}


Table .12: Parameter $C_{2}[\mathrm{~F}]$ for a charging current

\begin{tabular}{|c|c|c|c|c|c|c|c|c|c|c|c|}
\hline \multirow{2}{*}{ SoH [\%] } & \multicolumn{11}{|c|}{ SoC [\%] } \\
\hline & 0 & 5 & 10 & 20 & 30 & 50 & 70 & 80 & 90 & 95 & 100 \\
\hline 80 & 214.66 & 313.96 & 315.29 & 292.80 & 261.27 & 208.54 & 328.22 & 270.37 & 196.87 & 179.01 & 164.14 \\
\hline 75 & 199.94 & 242.35 & 249.18 & 233.58 & 207.05 & 185.28 & 295.85 & 261.73 & 153.10 & 138.36 & 123.62 \\
\hline 70 & 201.00 & 211.61 & 222.25 & 204.02 & 181.83 & 190.51 & 256.26 & 239.29 & 132.07 & 117.33 & 102.59 \\
\hline 65 & 209.21 & 199.51 & 201.15 & 181.89 & 167.67 & 199.23 & 243.72 & 226.22 & 122.67 & 107.91 & 93.15 \\
\hline 60 & 203.11 & 191.60 & 186.49 & 171.66 & 163.08 & 196.99 & 222.46 & 215.36 & 123.05 & 107.77 & 92.49 \\
\hline 55 & 196.63 & 182.77 & 174.67 & 164.40 & 161.32 & 193.62 & 198.47 & 208.36 & 124.35 & 108.54 & $\begin{array}{l}92.74 \\
\end{array}$ \\
\hline 50 & 194.67 & 177.47 & 170.96 & 167.64 & 168.73 & 198.43 & 203.86 & 199.56 & 124.10 & 110.38 & 96.66 \\
\hline
\end{tabular}

Table .13: Parameter $C_{2}[\mathrm{~F}]$ for a discharging current

\begin{tabular}{||c||c|c|c|c|c|c|c|c|c|c|c||}
\hline \multirow{2}{*}{$\begin{array}{c}\text { SoH }[\%] \\
\mathbf{8 0}\end{array}$} & $\mathbf{0}$ & $\mathbf{5}$ & $\mathbf{1 0}$ & $\mathbf{2 0}$ & $\mathbf{3 0}$ & $\mathbf{5 0}$ & $\mathbf{7 0}$ & $\mathbf{8 0}$ & $\mathbf{9 0}$ & $\mathbf{9 5}$ & $\mathbf{1 0 0}$ \\
\cline { 2 - 12 } $\mathbf{7 5}$ & 56.09 & 120.30 & 166.59 & 236.77 & 283.19 & 306.07 & 270.36 & 263.36 & 256.00 & 299.24 & 268.11 \\
\cline { 2 - 12 } & 57.94 & 128.56 & 161.82 & 215.67 & 254.01 & 262.67 & 259.20 & 250.40 & 249.32 & 274.75 & 242.50 \\
\cline { 2 - 12 } & 51.16 & 129.64 & 155.23 & 197.90 & 232.10 & 226.06 & 242.50 & 236.01 & 237.66 & 259.22 & 215.69 \\
$\mathbf{6 5}$ & 73.83 & 142.51 & 163.88 & 191.67 & 225.09 & 211.06 & 240.61 & 227.02 & 230.23 & 251.70 & 206.66 \\
$\mathbf{6 0}$ & 115.34 & 162.80 & 176.46 & 192.68 & 219.04 & 197.41 & 238.21 & 224.60 & 230.59 & 249.34 & 202.06 \\
$\mathbf{5 5}$ & 154.03 & 181.31 & 187.58 & 194.51 & 209.39 & 183.39 & 237.55 & 221.04 & 230.63 & 244.46 & 199.87 \\
$\mathbf{5 0}$ & 185.4 & 190.61 & 194.42 & 189.54 & 195.22 & 195.15 & 237.48 & 216.37 & 231.80 & 240.04 & 202.77 \\
\hline
\end{tabular}

Table .14: Parameter $V_{o c}[\mathrm{~V}]$

\begin{tabular}{|c|c|c|c|c|c|c|c|c|c|c|c|}
\hline \multirow{2}{*}{ SoH [\%] } & \multicolumn{11}{|c|}{ SoC [\%] } \\
\hline & 0 & 5 & 10 & 20 & 30 & 50 & 70 & 80 & 90 & 95 & 100 \\
\hline 80 & 3.33 & 3.48 & 3.50 & 3.57 & 3.62 & 3.72 & 3.90 & 3.98 & 4.06 & 4.10 & 4.16 \\
\hline 75 & 3.40 & 3.49 & 3.52 & 3.58 & 3.63 & 3.74 & 3.90 & 3.98 & 4.06 & 4.10 & 4.16 \\
\hline 70 & 3.44 & 3.50 & 3.53 & 3.59 & 3.63 & 3.75 & 3.91 & 3.98 & 4.06 & 4.09 & 4.15 \\
\hline 65 & 3.47 & 3.52 & 3.55 & 3.60 & 3.65 & $\begin{array}{l}3.77 \\
\end{array}$ & 3.91 & 3.98 & 4.06 & 4.09 & 4.15 \\
\hline 60 & 3.50 & 3.54 & 3.57 & 3.62 & 3.67 & $\begin{array}{l}3.79 \\
\end{array}$ & 3.93 & 3.99 & 4.06 & 4.10 & 4.14 \\
\hline 55 & 3.53 & 3.57 & 3.60 & 3.64 & 3.69 & 3.81 & 3.94 & 4.00 & 4.06 & 4.10 & 4.14 \\
\hline 50 & 3.56 & 3.60 & 3.62 & 3.67 & 3.72 & 3.84 & 3.96 & 4.01 & 4.07 & 4.10 & 4.14 \\
\hline
\end{tabular}


APPENDIX B - Parameters for Model FL0 ${ }^{\circ} \mathrm{C}$ :

Table .15: Parameter $R_{\text {int }}[\Omega]$ for a charging current

\begin{tabular}{|c|c|c|c|c|c|c|c|c|c|c|c|}
\hline \multirow{2}{*}{ SoH [\%] } & \multicolumn{11}{|c|}{ SoC [\%] } \\
\hline & 0 & 5 & 10 & 20 & 30 & 50 & 70 & 80 & 90 & 95 & 100 \\
\hline 80 & 0.0498 & 0.0481 & 0.0467 & 0.0454 & 0.0445 & 0.0432 & 0.0413 & 0.0409 & 0.0417 & 0.0434 & 0.0456 \\
\hline 75 & 0.0614 & 0.0583 & 0.0582 & 0.056 & 0.0558 & 0.0525 & 0.0483 & 0.0475 & 0.048 & 0.0504 & 0.0536 \\
\hline 70 & 0.0641 & 0.0626 & 0.0608 & 0.0589 & 0.0593 & 0.0547 & 0.0502 & 0.0496 & 0.0502 & 0.0531 & 0.0564 \\
\hline 65 & 0.0664 & 0.0659 & 0.0632 & 0.0627 & 0.0615 & 0.0561 & 0.0518 & 0.0519 & 0.0524 & 0.0546 & 0.0572 \\
\hline 60 & 0.07 & 0.0685 & 0.0663 & 0.0657 & 0.0639 & 0.0586 & 0.055 & 0.0551 & 0.056 & 0.0582 & 0.0609 \\
\hline 55 & 0.0744 & 0.0718 & 0.07 & 0.0689 & 0.0665 & 0.0615 & 0.0588 & 0.0587 & 0.0599 & 0.0621 & 0.065 \\
\hline 50 & 0.0794 & 0.0764 & 0.0742 & 0.0719 & 0.0692 & 0.0649 & 0.0629 & 0.0627 & 0.0641 & 0.0662 & 0.069 \\
\hline
\end{tabular}

Table .16: Parameter $R_{\text {int }}[\Omega]$ for a discharging current

\begin{tabular}{|c|c|c|c|c|c|c|c|c|c|c|c|}
\hline \multirow{2}{*}{ SoH [\%] } & \multicolumn{11}{|c|}{ SoC [\%] } \\
\hline & 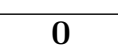 & 5 & 10 & 20 & 30 & 50 & 70 & 80 & 90 & 95 & 100 \\
\hline 80 & 0.0517 & 0.0496 & 0.0476 & 0.0458 & 0.0445 & 0.0438 & 0.0427 & 0.0426 & 0.0427 & 0.0432 & 0.044 \\
\hline 75 & 0.06 & 0.0587 & 0.0583 & 0.056 & 0.0555 & 0.0524 & 0.0495 & 0.0488 & 0.0492 & 0.0501 & 0.051 \\
\hline 70 & 0.0627 & 0.0619 & 0.0612 & 0.0594 & 0.059 & 0.0558 & 0.0517 & 0.0511 & 0.0512 & 0.0521 & 0.0532 \\
\hline 65 & 0.0655 & 0.0652 & 0.0638 & 0.0637 & 0.0619 & 0.0584 & 0.0545 & 0.0538 & 0.0537 & 0.0543 & 0.0551 \\
\hline 60 & 0.0694 & 0.0691 & 0.0686 & 0.0682 & 0.0669 & 0.0624 & 0.058 & 0.0575 & 0.057 & 0.0572 & 0.0582 \\
\hline 55 & 0.0739 & 0.0735 & 0.0739 & 0.0733 & 0.0728 & 0.0668 & 0.0621 & 0.0617 & 0.0608 & 0.0607 & 0.0618 \\
\hline 50 & 0.0791 & 0.0788 & 0.079 & 0.0787 & 0.0785 & 0.0715 & 0.0667 & 0.066 & 0.0651 & 0.0648 & 0.0659 \\
\hline
\end{tabular}

Table .17: Parameter $R_{1}[\Omega]$ for a charging current

\begin{tabular}{|c|c|c|c|c|c|c|c|c|c|c|c|}
\hline \multirow{2}{*}{ SoH [\%] } & \multicolumn{11}{|c|}{ SoC [\%] } \\
\hline & 0 & 5 & 10 & 20 & 30 & 50 & 70 & 80 & 90 & 95 & 100 \\
\hline 80 & 0.0049 & 0.0026 & 0.002 & 0.002 & 0.0029 & 0.0039 & 0.0039 & 0.004 & 0.0049 & 0.0055 & 0.0061 \\
\hline 75 & 0.0183 & 0.0141 & 0.0112 & 0.0102 & 0.0092 & 0.0076 & 0.006 & 0.0065 & 0.0089 & 0.0098 & 0.0108 \\
\hline 70 & 0.0183 & 0.0147 & 0.0143 & 0.0129 & 0.0115 & 0.008 & 0.0066 & 0.0071 & 0.0102 & 0.0111 & 0.0121 \\
\hline 65 & 0.0178 & 0.0147 & 0.0158 & 0.0136 & 0.013 & 0.008 & 0.0074 & 0.0074 & 0.0107 & 0.0116 & 0.0126 \\
\hline 60 & 0.0167 & 0.0153 & 0.0157 & 0.0134 & 0.0127 & 0.0082 & 0.0081 & 0.0082 & 0.011 & 0.0119 & 0.0129 \\
\hline 55 & 0.0159 & 0.0158 & 0.0153 & 0.013 & 0.0121 & 0.0084 & 0.0087 & 0.009 & 0.0114 & 0.0123 & 0.0133 \\
\hline 50 & 0.0155 & 0.0155 & 0.0147 & 0.0124 & 0.0114 & 0.0091 & 0.0095 & 0.0099 & 0.012 & 0.0128 & 0.0138 \\
\hline
\end{tabular}

Table .18: Parameter $R_{1}[\Omega]$ for a discharging current

\begin{tabular}{|c|c|c|c|c|c|c|c|c|c|c|c|}
\hline \multirow{2}{*}{ SoH [\%] } & \multicolumn{11}{|c|}{ SoC [\%] } \\
\hline & 0 & 5 & 10 & 20 & 30 & 50 & 70 & 80 & 90 & 95 & 100 \\
\hline 80 & 0.0127 & 0.0091 & 0.0062 & 0.004 & 0.0035 & 0.0041 & 0.0047 & 0.0054 & 0.0057 & 0.006 & 0.0056 \\
\hline 75 & 0.0227 & 0.0206 & 0.0158 & 0.0135 & 0.0106 & 0.0103 & 0.0065 & 0.0078 & 0.008 & 0.0095 & 0.0101 \\
\hline 70 & 0.0249 & 0.0219 & 0.0182 & 0.0158 & 0.0137 & 0.0122 & 0.0073 & 0.0087 & 0.0087 & 0.0106 & 0.0111 \\
\hline 65 & 0.0249 & 0.0212 & 0.0191 & 0.016 & 0.0157 & 0.0129 & 0.008 & 0.0093 & 0.009 & 0.011 & 0.0117 \\
\hline 60 & 0.0244 & 0.0209 & 0.0191 & 0.0167 & 0.0165 & 0.0128 & 0.0088 & 0.0098 & 0.0093 & 0.0115 & 0.0119 \\
\hline 55 & 0.0239 & 0.0208 & 0.0191 & 0.0174 & 0.0169 & 0.0124 & 0.0095 & 0.0103 & 0.0096 & 0.0118 & 0.012 \\
\hline 50 & 0.0243 & 0.0208 & 0.0198 & 0.0182 & 0.0177 & 0.0121 & 0.0101 & 0.0107 & 0.0101 & 0.0121 & 0.0122 \\
\hline
\end{tabular}


Table .19: Parameter $R_{2}[\Omega]$ for a charging current

\begin{tabular}{|c|c|c|c|c|c|c|c|c|c|c|c|}
\hline \multirow{2}{*}{ SoH [\%] } & \multicolumn{11}{|c|}{ SoC [\%] } \\
\hline & 0 & 5 & 10 & 20 & 30 & 50 & 70 & 80 & 90 & 95 & 100 \\
\hline 80 & 0.0276 & 0.0187 & 0.0179 & 0.017 & 0.0183 & 0.0208 & 0.0238 & 0.0288 & 0.0359 & 0.041 & 0.0457 \\
\hline 75 & 0.0557 & 0.0291 & 0.0303 & 0.0268 & 0.0279 & 0.0343 & 0.0313 & 0.0354 & 0.0463 & 0.0504 & 0.055 \\
\hline 70 & 0.0489 & 0.032 & 0.0325 & 0.0294 & 0.0318 & 0.0377 & 0.037 & 0.0406 & 0.0494 & 0.0532 & 0.0573 \\
\hline 65 & 0.0374 & 0.0347 & 0.0345 & 0.0326 & 0.0357 & 0.0396 & 0.0418 & 0.0467 & 0.0525 & 0.0558 & 0.0593 \\
\hline 60 & 0.0351 & 0.0363 & 0.0362 & 0.0359 & 0.0396 & 0.0428 & 0.0457 & 0.0542 & 0.0579 & 0.0609 & 0.0641 \\
\hline 55 & 0.036 & 0.0377 & 0.0382 & 0.0396 & 0.0435 & 0.047 & 0.0495 & 0.0605 & 0.0631 & 0.066 & 0.0691 \\
\hline 50 & 0.0389 & 0.0389 & 0.0408 & 0.0435 & 0.0465 & 0.0531 & 0.0538 & 0.0631 & 0.0665 & 0.0694 & 0.0725 \\
\hline
\end{tabular}

Table .20: Parameter $R_{2}[\Omega]$ for a discharging current

\begin{tabular}{|c|c|c|c|c|c|c|c|c|c|c|c|}
\hline \multirow{2}{*}{ SoH [\%] } & \multicolumn{11}{|c|}{ SoC [\%] } \\
\hline & 0 & 5 & 10 & 20 & 30 & 50 & 70 & 80 & 90 & 95 & 100 \\
\hline 80 & 0.0748 & 0.0554 & $\begin{array}{c}0.0376 \\
\end{array}$ & 0.0251 & 0.0225 & 0.0222 & 0.0216 & 0.0211 & 0.0205 & 0.0195 & 0.0206 \\
\hline 75 & 0.0858 & 0.0685 & 0.0493 & 0.0315 & 0.031 & 0.0327 & 0.0309 & 0.0315 & 0.0313 & 0.0292 & 0.0301 \\
\hline 70 & 0.0895 & 0.0687 & 0.0505 & 0.0349 & 0.0351 & 0.0392 & 0.0363 & 0.0355 & 0.0363 & 0.0332 & 0.0341 \\
\hline 65 & 0.0922 & 0.0672 & 0.0514 & 0.039 & 0.039 & 0.0448 & 0.0421 & 0.0392 & 0.0411 & 0.0364 & 0.0375 \\
\hline 60 & 0.0882 & 0.0662 & 0.0551 & 0.0449 & 0.0472 & 0.0539 & 0.0478 & 0.0441 & 0.0451 & 0.0397 & 0.0406 \\
\hline 55 & 0.0828 & 0.066 & 0.0594 & 0.0518 & 0.0573 & 0.0645 & 0.0536 & 0.0495 & 0.0491 & 0.0433 & 0.0438 \\
\hline 50 & 0.0799 & 0.0677 & 0.0641 & 0.0596 & 0.0688 & 0.0777 & 0.0602 & 0.0546 & 0.0534 & 0.047 & 0.0471 \\
\hline
\end{tabular}

Table .21: Parameter $C_{1}[\mathrm{~F}]$ for a charging current

\begin{tabular}{|c|c|c|c|c|c|c|c|c|c|c|c|}
\hline \multirow{2}{*}{ SoH [\%] } & \multicolumn{11}{|c|}{ SoC [\%] } \\
\hline & 0 & 5 & 10 & 20 & 30 & 50 & 70 & 80 & 90 & 95 & 100 \\
\hline 80 & 85.62 & 1110.78 & 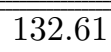 & $\begin{array}{l}162.73 \\
\end{array}$ & 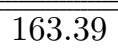 & 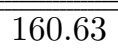 & $\bar{~} 172.82$ & 177.72 & 250.43 & 291.67 & $\overline{322.8}$ \\
\hline 75 & 26.31 & 30.93 & 38.83 & 39.08 & 52.23 & 89.09 & 139.29 & 140.15 & 176.71 & 190.41 & 204.66 \\
\hline 70 & 25.84 & 30.51 & 29.76 & 31.31 & 43.84 & 94.87 & 130.85 & 124.7 & 165.82 & 178.69 & 192.08 \\
\hline 65 & 24.83 & 29.99 & 24.38 & 30.79 & 38.97 & 98.62 & 104.28 & 120.69 & 155.46 & 167.49 & 179.99 \\
\hline 60 & 27.18 & 30.32 & 25.23 & 34.38 & 42.82 & 98.45 & 102.05 & 122.93 & 155.06 & 166.82 & 179.03 \\
\hline 55 & 30.63 & 31.56 & 29.11 & 40.47 & 49.84 & 96.61 & 107.38 & 128.36 & 159.24 & 171.06 & 183.33 \\
\hline 50 & 33.81 & 34.02 & 34.59 & 48.75 & 59.59 & 92.3 & 117.32 & 138.77 & 167.9 & 180.21 & 193.01 \\
\hline
\end{tabular}

Table .22: Parameter $C_{1}[\mathrm{~F}]$ for a discharging current

\begin{tabular}{|c|c|c|c|c|c|c|c|c|c|c|c|}
\hline \multirow{2}{*}{ SoH [\%] } & \multicolumn{11}{|c|}{ SoC [\%] } \\
\hline & 0 & 5 & 10 & 20 & 30 & 50 & 70 & 80 & 90 & 95 & 100 \\
\hline 80 & 32.1 & 51.04 & 70.99 & 97.38 & 117.49 & 138.18 & 157.65 & 148.7 & 131.61 & 113.33 & 110.97 \\
\hline 75 & 28.37 & 24.91 & 32.3 & 35.6 & 45.2 & 73.34 & 137.17 & 113.98 & 106.8 & 86.9 & 66.83 \\
\hline 70 & 26.97 & 23.23 & 27.2 & 29.79 & 35.75 & 64.99 & 112.12 & 96.23 & 97.42 & 76.5 & 65.82 \\
\hline 65 & 26.61 & 23.61 & 23.85 & 28.25 & 29.78 & 59.08 & 111.17 & 90.37 & 96.61 & 73.86 & 62.78 \\
\hline 60 & 25.99 & 23.35 & 23.94 & 27.31 & 28.48 & 58.47 & 97.81 & 87.35 & 90.8 & 68.53 & 61.28 \\
\hline 55 & 25.49 & 23.19 & 24.7 & 27.36 & 29.54 & 59.73 & 86.86 & 85.73 & 86.51 & 64.24 & 60.46 \\
\hline 50 & 26.23 & 23.67 & 24.32 & 27.73 & 30.81 & 59.8 & 81.61 & 81.71 & 82.31 & 61.65 & 59.28 \\
\hline
\end{tabular}


Table .23: Parameter $C_{2}[\mathrm{~F}]$ for a charging current

\begin{tabular}{|c|c|c|c|c|c|c|c|c|c|c|c|}
\hline \multirow{2}{*}{ SoH [\%] } & \multicolumn{11}{|c|}{ SoC [\%] } \\
\hline & 0 & 5 & 10 & 20 & 30 & 50 & 70 & 80 & 90 & 95 & 100 \\
\hline 80 & 382.94 & 459.6 & 465.31 & 468.77 & 440.41 & 415.2 & 478.47 & 439.64 & 384.64 & 346.65 & 318.22 \\
\hline 75 & 187.11 & 295.19 & 317.81 & 326.26 & 320.95 & 248.02 & 360.46 & 345.01 & 249.86 & 221.21 & 200.38 \\
\hline 70 & 209.6 & 283.49 & 284.53 & 285.51 & 273.82 & 240.26 & 321.96 & 314.88 & 226.51 & 197.87 & 177.03 \\
\hline 65 & 238.41 & 265.94 & 263.32 & 262.76 & 241.59 & 235.05 & 280.07 & 302.67 & 210.98 & 182.33 & 161.5 \\
\hline 60 & 263.61 & 256.12 & 246 & 242.01 & 223.17 & 229.37 & 267.63 & 297.31 & 202.91 & 174.26 & 153.43 \\
\hline 55 & 279.2 & 246.93 & 231.99 & 225.16 & 210.84 & 224.29 & 265.12 & 291.79 & 196.67 & 168.02 & 147.19 \\
\hline 50 & 273.32 & 236.54 & 219.24 & 213.9 & 204.68 & 218.46 & 271.51 & 281.86 & 189.7 & 161.05 & 140.22 \\
\hline
\end{tabular}

Table .24: Parameter $C_{2}[\mathrm{~F}]$ for a discharging current

\begin{tabular}{|c|c|c|c|c|c|c|c|c|c|c|c|}
\hline \multirow{2}{*}{ SoH [\%] } & \multicolumn{11}{|c|}{ SoC [\%] } \\
\hline & 0 & 5 & 10 & 20 & 30 & 50 & 70 & 80 & 90 & 95 & 100 \\
\hline 80 & 181.71 & 270.42 & 363.11 & 440.21 & 473.35 & 488.07 & 506.97 & 487.53 & 459.75 & 437.16 & 440.39 \\
\hline 75 & 91.8 & 184.45 & 254.8 & 317.3 & 330.93 & 277.49 & 336.42 & 303.73 & 308.76 & 290.33 & 286.55 \\
\hline 70 & 113.91 & 190.7 & 248 & 289.22 & 297.21 & 236.57 & 301.92 & 273.41 & 287.61 & 272.7 & 264.69 \\
\hline 65 & 138.46 & 201.33 & 248.54 & 274.33 & 271.45 & 204.69 & 296.12 & 263.77 & 280.93 & 264.5 & 250.97 \\
\hline 60 & 152.43 & 205.61 & 245.07 & 255.36 & 248.95 & 189.96 & 278.16 & 258.01 & 268.23 & 254.01 & 238.98 \\
\hline 55 & 158 & 207 & 238.04 & 236.78 & 229.72 & 179.9 & 260.07 & 253.32 & 256.17 & 243.93 & 227.38 \\
\hline 50 & 155.5 & 203.24 & 222.99 & 218.72 & 212.39 & 174.56 & 245.7 & 243.73 & 245.84 & 234.04 & 215.3 \\
\hline
\end{tabular}

Table .25: Parameter $V_{o c}[\mathrm{~V}]$

\begin{tabular}{|c|c|c|c|c|c|c|c|c|c|c|c|}
\hline \multirow{2}{*}{ SoH [\%] } & \multicolumn{11}{|c|}{ SoC [\%] } \\
\hline & 0 & 5 & 10 & 20 & 30 & 50 & 70 & 80 & 90 & 95 & 100 \\
\hline 80 & 3.48 & 3.51 & 3.54 & 3.58 & 3.64 & 3.76 & 3.91 & 4.01 & 4.08 & 4.13 & 4.17 \\
\hline 75 & 3.38 & 3.49 & 3.53 & 3.59 & 3.64 & 3.77 & 3.93 & 4 & 4.08 & 4.12 & 4.18 \\
\hline 70 & 3.42 & 3.51 & 3.54 & 3.6 & 3.65 & 3.78 & 3.93 & 4.01 & 4.08 & 4.12 & 4.17 \\
\hline 65 & 3.47 & 3.52 & 3.56 & 3.61 & 3.66 & 3.8 & 3.94 & 4.01 & 4.08 & 4.12 & 4.17 \\
\hline 60 & 3.5 & 3.55 & 3.58 & 3.63 & 3.68 & 3.82 & 3.95 & 4.02 & 4.08 & 4.12 & 4.16 \\
\hline 55 & 3.53 & 3.57 & 3.6 & 3.66 & 3.71 & 3.84 & 3.96 & 4.03 & 4.09 & 4.12 & 4.16 \\
\hline 50 & 3.56 & 3.6 & 3.63 & 3.68 & 3.73 & 3.86 & 3.98 & 4.03 & 4.09 & 4.12 & 4.16 \\
\hline
\end{tabular}

